\title{
State of the Art and Trends in the Monitoring, Detection and Diagnosis of Failures in Electric Induction Motors
}

\author{
Yuri Merizalde ${ }^{1}$, Luis Hernández-Callejo ${ }^{2, *}$ and Oscar Duque-Perez ${ }^{3}$ \\ 1 PhD School of University of Valladolid (UVA), Faculty of Chemical Engineering, University of Guayaquil, \\ Clemente Ballen 2709 and Ismael Perez Pazmiño, Guayaquil 593, Ecuador; \\ yuryhumberto.merizalde@alumnos.uva.es \\ 2 Department of Agricultural Engineering and Forestry, University of Valladolid (UVA), Campus \\ Universitario Duques de Soria, 42004 Soria, Spain \\ 3 Department of Electrical Engineering, University of Valladolid (UVA), Escuela de Ingenierías Industriales, \\ Paseo del Cauce 59, 47011 Valladolid, Spain; oscar.duque@eii.uva.es \\ * Correspondence: luis.hernandez.callejo@uva.es; Tel.: +34-975-129-213
}

Academic Editor: K.T. Chau

Received: 17 June 2017; Accepted: 3 July 2017; Published: 21 July 2017

\begin{abstract}
Despite the complex mathematical models and physical phenomena on which it is based, the simplicity of its construction, its affordability, the versatility of its applications and the relative ease of its control have made the electric induction motor an essential element in a considerable number of processes at the industrial and domestic levels, in which it converts electrical energy into mechanical energy. The importance of this type of machine for the continuity of operation, mainly in industry, is such that, in addition to being an important part of the study programs of careers related to this branch of electrical engineering, a large number of investigations into monitoring, detecting and quickly diagnosing its incipient faults due to a variety of factors have been conducted. This bibliographic research aims to analyze the conceptual aspects of the first discoveries that served as the basis for the invention of the induction motor, ranging from the development of the Fourier series, the Fourier transform mathematical formula in its different forms and the measurement, treatment and analysis of signals to techniques based on artificial intelligence and soft computing. This research also includes topics of interest such as fault types and their classification according to the engine, software and hardware parts used and modern approaches or maintenance strategies.
\end{abstract}

Keywords: induction electric motors; maintenance strategies; types of faults; detection and diagnosis; monitoring; artificial intelligence

\section{Introduction}

The discovery of electric current and its transmission through wires opened a vast field of research related to the behavior, associated phenomena and practical applications of electricity. As a result of this, one of the most amazing and important inventions for the development of humanity was produced, the electric motor, as the result of the application of various laws of physics and abstract and complex mathematical models, such as Ampere's law, the Bio-Savart law and Maxwell's laws, which were discovered after many years of arduous investigative work and can be included among the most transcendental in history. However, one of the most amazing things is that despite the complexity of its foundations, its simple construction paradoxically makes the induction engine one of the simplest and most widely-used machines on the planet. 
In almost any activity of man, it is essential to use the electric induction motor: from our homes to the most complex industry, where the transformation between electrical and mechanical energy would not be possible without this type of electric machine. The intrinsic dependence that exists between electric motors, the continuity of operation at an industrial or micro-enterprise level and the financial profitability of any organization have motivated a great amount of investigations to be carried out to develop maintenance strategies and specific techniques for the monitoring, detection and diagnosis of the variety of faults that can occur in electric induction motors.

The objective of this article is to conduct a macro or global analysis of the different methodologies applied to diagnose the failures that can occur in an induction motor in a timely manner and to avoid its exit from service in an unexpected way. For this, the present work is organized into five sections.

The Section 2 includes the historical development of the foundations that serve as a basis for understanding the operation of electric induction motors and the principles upon which diagnostic techniques are based. The subsections are devoted to issues related to the types of failures, statistics and maintenance strategies. Section 3 focuses on invasive and non-invasive maintenance techniques, as well as the software and hardware used for monitoring, detection and diagnosis of failures. Section 4 analyzes the different types of failures and the techniques used to detect them according to the engine part. Section 5 includes the use of Artificial Intelligence (AI) techniques and Soft Computing (SC) for the detection of early failures. Finally, Section 6 addresses conclusions and recommendations.

\section{Historical Analysis of the Development of the Theoretical Foundations of Electric Induction Motors and Fault Types and Statistics}

\subsection{Historical Analysis of the Development of the Theoretical Foundations of Electric Induction Motors}

Since ancient times, man has been familiar with materials that have the unique property of attracting certain objects. It was also known that, when rubbing amber with the skin, this stone acquired the ability to attract pieces of grass [1,2]. According to Shu-hua [3], during the Fourth Century BC in the city of Magnesia, the existence of a material called magnetite that could attract iron was known. According to the same author, years later, Chinese civilization would record several events related to the use of a magnetized needle that could indicate the geographic north or south of the planet. Although initially there was no scientific development that could explain electromagnetic phenomena, this would have been observed and applied many centuries ago; it could even be said that man has always lived with it [4-7].

Charles Coulomb was able to measure the small forces of attraction or repulsion exercised between electrically loaded pieces of paper or grass for the first time in 1785; he found that the measured force behaved just like Newton's law of universal gravitation. In 1800, Alessandro Volta demonstrated that he could produce sparks and other electrical effects by stacking copper and zinc disks separated by wet cardboard, which would become the origin of batteries and one of the first continuous sources of electric power. In 1820, the Danish physicist Hans Christian Oersted demonstrated that an electric current generates a magnetic field that can interact with another field (that produced by a magnetized material) [1].

German physicist and chemist Johann Schweigger found that the effect of a current on a magnetized needle discovered by Oersted could be improved by replacing the conductor with a coil made of several wire turns, which would later be known as a galvanometer. In England, William Sturgeon wrapped wire on a steel horseshoe, resulting in an electromagnet, stronger than any natural magnetic material that was known until then [1]. The magnetic field created in a conductor would be negligible such that for practical uses, it is necessary to increase it; this is achieved by winding several turns of wire (coil) on a core that is usually made of ferromagnetic iron. The iron core is of low reluctance; it avoids dispersion, and it concentrates the lines of the magnetic field, increasing the flow and its density within allowable limits before saturation. The number of turns $N$ multiplied by the current I is known as the Magnetomotive Force (MMF) [8]. William Sturgeon had 
reproduced or found the equivalent of magnetic stones, whereas Oersted and Schweigger had reproduced the same phenomenon that occurred naturally between a magnetized needle and the magnetic field of the Earth.

Kline [9] states, "In 1824 Francois Arago found that a magnetized needle suspended on a copper disk could be rotated when the latter was rotated." According to the author, this discovery together with the production of a rotating magnetic field through electricity would be the foundation of the induction motor. In 1821, Michael Faraday demonstrated that a conductor conducting an electric current could rotate permanently in the presence of a magnetic field, and in 1831, he would discover the principle of electromagnetic induction, according to which a variable magnetic field can induce an electric current into a conductor. He further established the concept of lines of force associated with the magnetic field, which would become the foundation of electromagnetic theory [4]. According to Faraday's principle of electromagnetic induction, if a conductor is within a variable magnetic field, then a voltage (emf) directly proportional to the change rate of the magnetic flux will be induced between the conductor terminals through the circuit. According to [10], this voltage can be obtained in a coil from the laws of Maxwell (1).

$$
\begin{gathered}
\oint_{l} E d l=-\frac{d}{d t} \int_{S} B d s=-\frac{d \Phi}{d t^{\prime}} \\
e=-k_{w} N \frac{d}{d t} \int_{S} B d s=-k_{w} N \frac{d \Phi}{d t}=-k_{w} N \frac{d(B A \cos \theta)}{d t}
\end{gathered}
$$

where:

$e=$ Electromotive force (volts)

$k_{w}=$ Design factor of the machine

$N=$ Number of coil turns

$\Phi=$ Magnetic flux (webers)

$B=$ Flux density (Teslas)

$A=$ Transversal section crossed by the flow $\left(\mathrm{m}^{2}\right)$

Based on the discoveries made by Michael Faraday, the first electric motors were built, which would be the forerunners of modern generators, motors and all types of electrical devices. One of the first types of equipment to be tested would be an alternating current generator consisting of two permanent magnet poles, which induced a voltage in a winding rotor when rotated; however, as the alternating current was not used initially, two slip rings were added to the rotor in such a way that continuous current was obtained from brushes. In 1850, a generator with a primary steam engine was already being used. In 1860, the permanent magnets were replaced by electromagnets, and in 1867, Werner von Siemens, Charles Wheatstone and Samuel Varley developed the Dynamo almost simultaneously. Due to the instability of the voltage produced by the machines designed until then, in 1870, Zénobe-Théphile Gramme created an improved version of the dynamo that replaced the single poles by several coils arranged on an iron core that covered the entire stator. Later, he would demonstrate that his Dynamo could also function as a motor [1].

The disadvantages of DC machines; and the achievement obtained by Zénobe-Théphile Gramme in making the Dynamo work as a motor all served as precedent for Nicola Tesla to invent and patent the first induction AC motor in 1888. This machine consisted of a winding rotor and a stator of four salient poles, which did not cover the entire stator. Despite the significant advances of Nicola Tesla, the insufficient starting torque, its low performance, the high frequency of the network and the lack of polyphase generation and distribution systems meant that this motor could not be exploited commercially on a large scale. Charles Brown and Michael Dolivo-Dobrolowsky would improve the work of Tesla by developing the wound rotor and squirrel cage-type induction motor as we know it today [1].

Research on the construction of induction motors conducted by Dolivo-Dobrolowsky led him to deduce that to build AC motor, the distortion of the flux had to be minimized, and the resistance of the rotor had to be higher at the start than when at nominal speed. In 1891 in the city of Frankfurt, Michael Dolivo-Dobrolowsky exhibited the use of a three-phase motor of $100 \mathrm{hp}$ to pump water, for 
which he had inverted the rotor with the stator. In the same exhibition, Charles Brown (who had also developed a pioneering 3-phase generation and transmission system for the city of Frankfurt) presented a three-phase induction engine of $20 \mathrm{hp}$, with an efficiency of 90 percent, which was used to operate a fan. Brown's engine consisted of a primary stator whose core included slots over the entire periphery and whose interior housed the winding that was connected to the network. The rotor consisted of a drum with slots on its outer periphery in which insulated copper bars were installed, the same are short circuit at the ends through rings. Brown's engine proved to be more efficient, simple, economical and versatile than that designed by Dolivo-Dobrolowsky. However, he had the disadvantage of low starting torque. This would be solved in 1920 when General Electric, Westinghouse, and AEG perfected the induction motor with a rotor that had a double squirrel cage [9].

Today, one-third of the total electric energy generated is converted into mechanical energy by electric induction motors employed in all types of activities and environments. Its simplicity compared to other types of dynamic electric machines has made it one of the most useful inventions [9]. According to Trzynadlowski [11], "Induction motors, the primary workhorse of industry, consume over $60 \%$ of the total electric power produced in the USA." Without a doubt, within the area of electric machines, the induction motor occupies a preponderant place and has become one of the main research topics of new design, construction and maintenance techniques, perhaps because the investigations conducted thus far apply to a wide variety of equipment.

The induction motor is very simple and consists of two main parts: the stator and the rotor. In addition, the induction motors used in industrial areas are mostly three-phase which compared to DC motors or single-phase AC motors of the same capacity, are much smaller, lighter, economical and have a lower starting current [10].

At present, the monitoring of the state of the motor is done mainly by the analysis of the signals such as the current, which has an undulatory behavior [12]. For this reason, from the historical point of view and theoretical foundations we could start this part mentioned to James Maxwell. In his work "A Dynamical Theory of the Electromagnetic Field", published in 1864, Maxwell presented a mathematical formulation that related the electrical, magnetic, light undulatory behavior and energy of the wave theories. Subsequent works of other scientists, such as Oliver Heaviside, allowed for summarization of this theory in four equations that demonstrate the theory of Maxwell in a more practical and comprehensible way [1]. From the equations of Maxwell, we can deduce the equation that represents the wave behavior of the magnetic flux in the air gap, the voltage and the current in terms of time and position [13]. The main wave and its components of these periodic sinusoidal signals can be represented by a convergent series of trigonometric functions, that is, the Fourier series (3), Ferreira and Van der Merwe [14].

$$
\begin{gathered}
f(t)=a_{v}+\sum_{n=1}^{\infty}\left(a_{n} \cos n \omega t+b_{n} \sin n \omega t\right), \\
a_{v}=\frac{1}{T} \int_{t_{0}}^{t_{0}+T} f(t) d t \\
a_{n}=\frac{2}{T} \int_{t_{0}}^{t_{0}+T} f(t) \cos n \omega t d t \\
\omega=2 \pi \mathrm{f}=2 \pi / \mathrm{T}
\end{gathered}
$$

$f=$ Frequency $; T=$ Signal period .

Discarding the DC component, according to [14], (3) can be written in accordance with its fundamental wave and its harmonics.

$$
f(t)=V_{1} \cos \left(\omega t+\theta_{1}\right)+\sum_{n=2}^{\infty} V_{n} \cos \left(n \omega t+\theta_{n}\right),
$$

where:

$f(t)=$ Signal as a function of time.

$V_{1}=$ Signal magnitude.

$\theta=$ Phase angle difference. 
The representation of a signal in the time domain allows us to know some parameters, such as amplitude, frequency, phase, and modulation. Notwithstanding, when it is necessary to know the origin or causes of any anomaly, it is preferable to carry out the study of the frequency domain (see Figure 1), and this is done with the help of Fourier analysis [15].

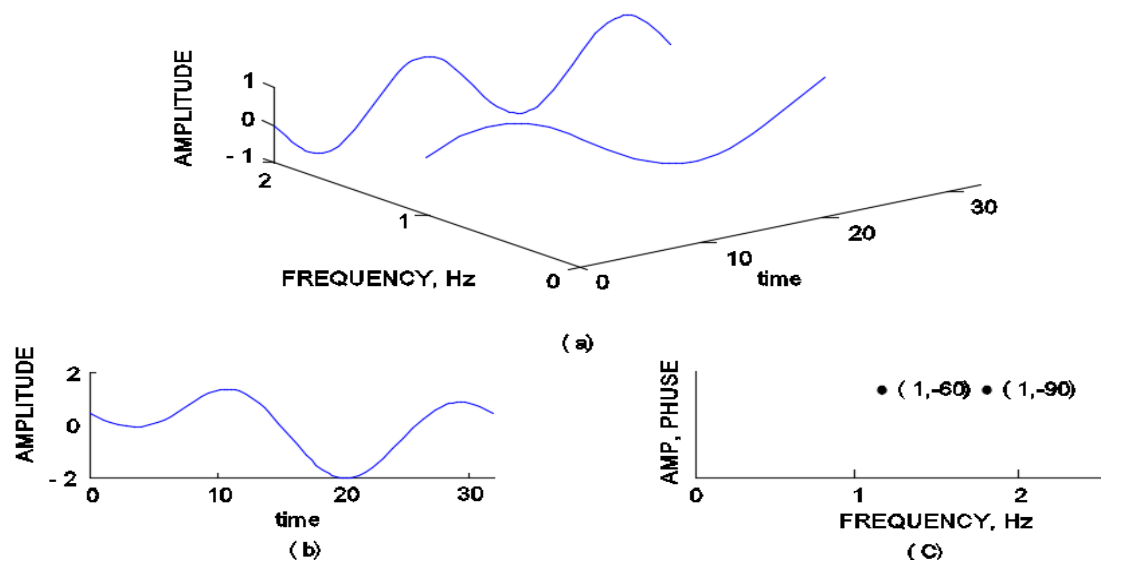

Figure 1. Representation of a signal in the time and frequency domains. (a) Two components of the same signal; (b) Time-domain representation; (c) Frequency-domain representation, as shown in [15].

According to Hansen [16], a periodic and continuous signal can be converted into an aperiodic and discrete signal by using the Discrete Fourier Transform (DFT). This signal can be transformed back into a continuous one by using the Discrete-Time Fourier Transform (DTFT) after exchanging the domains of time and frequency, i.e., by making the first discrete and the second continuous; see Figure 2.

The DFT in its most basic form can be written according to (8). The complex calculations to be performed are proportional to $N^{2}$ and $N \log _{2} N$ ( $N$ is the number of samples of the signal), which represent a substantial quantity. For this reason, several algorithms used to obtain the DTF make the most of the repetition of the operations, the symmetry and the periodicity of functions to facilitate and streamline the calculation. This methodology is known as the Fast Fourier Transform (FFT) (9). The energy and spectral density are given by (10) and (11), respectively, and the latter is known as the Wiener-Khintchine theorem [17].
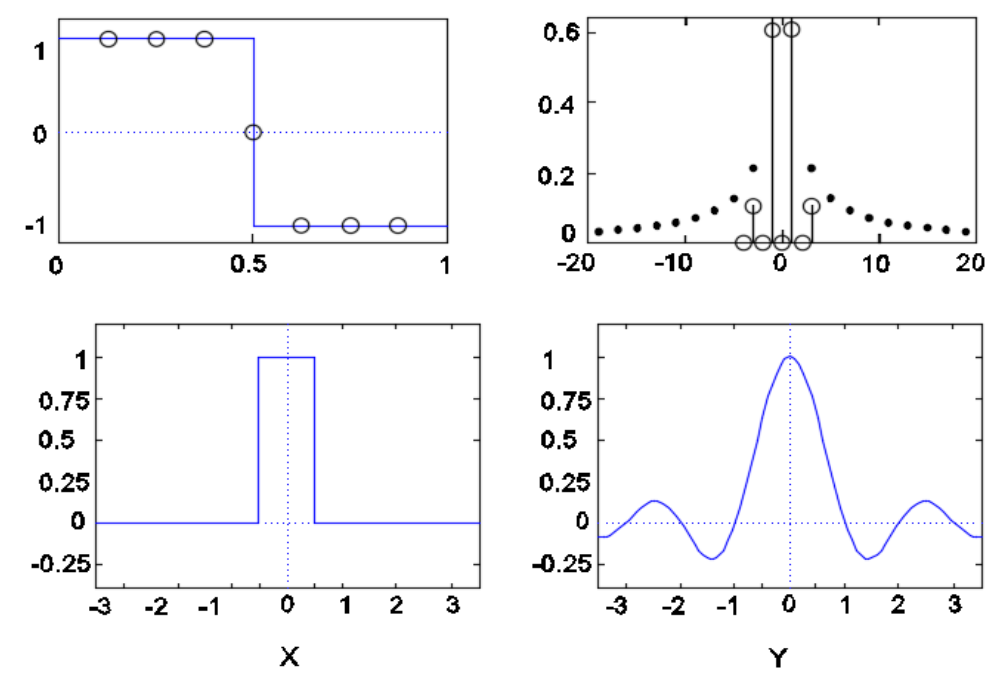

Figure 2. Conversion of a continuous signal to discrete and newly continuous through the Fourier transforms, as shown in [16]. Reproduced with permission from John Wiley and Sons, 2017. 


$$
\begin{gathered}
X_{N} k \frac{\omega_{S}}{N}=\sum_{n=0}^{N-1} x_{N}(n) e^{-j 2 \pi(k n / N)}=\sum_{n=0}^{N-1} x_{N}(n) W_{N}^{k n}, \\
X_{N} k \frac{\omega_{S}}{N}=\sum_{n=0}^{N-1} x_{N}(n) W_{N}^{k n}=\sum_{n=0}^{(N / 2)-1} x_{N}(2 n) W_{N / 2}^{k n}+W_{N}^{k} \sum_{n=0}^{(N / 2)-1} x_{N}(2 n+1) W_{N / 2}^{k n} \\
\sum_{n=-\infty}^{\infty}|x(n)|^{2}=\frac{1}{2 \pi} \int_{-\pi}^{\pi}|x(n)|^{2} d \omega=\frac{1}{2 \pi} \int_{-\pi}^{\pi} S_{x x} d \omega \\
\Phi_{x x}(\omega)=\sum_{k=-\infty}^{\infty} R_{x x}(k) e^{-j 2 \pi\left(\omega / \omega_{s}\right) k}
\end{gathered}
$$

The DFT is the primary computational tool for the spectrum analysis of a signal, the same that is modeled as a sum of sinusoids in which the protruding frequencies can be distinguished. Performing the diagnosis by analyzing the signal in the time or the frequency domain independently, can be improved by using the time-frequency representation (TFR). It can be further improved by using the TFR directly classified in the Doppler ambiguous plane to extract the vectors associated with the failures. The authors proposes a decision criterion based on the "distance of Mahalanobis" to obtain a safe diagnosis of broken bars, bearing and stator failures $[15,16,18]$.

Regardless of the methodology used, as we will see below, the monitoring, detection and diagnosis of faults in induction motors, are based on the use of the FFT as the main tool for the analysis of the signals.

\subsection{Types of Failures of Induction Motors and Occurrence Statistics}

Many factors contribute to the deterioration of the conditions of an engine and the occurrence of several types of faults. For this reason, the failures of the electric motors can be classified from different points of view, such as showed in Tables $1-3$. Table $1[19,20]$, shows a tentative grouping, according to the factors of the environment to which the engine is exposed and that could cause the appearance of the faults. A factor can belong to more than one group in many cases. Table 2 [19], Includes electrical and mechanical faults of the motor grouped as they occur in the rotor or stator and according to the factors that cause them, while Table 3 [15,19-22], broadens and shows another way of presenting the information in Table 2 .

There are many studies that note the most common failures. Table 4 [19] shows several statistics ordered according to the source of the studies. Although there are no coincidences regarding values, we can observe that the trend is very similar for the cases that are included. Thus, it could be generalized that the parts with greater frequencies of failures, ordered from greatest to least, would be the bearings, stator and rotor. O'Donnell [21] determined the contribution of the different types of faults in electrical motors over $200 \mathrm{hp}$ and with an age of less than 15 years. One of the most interesting parts of the study is the wide variety of failures that are included and their classification, see Tables 5 and 6 .

Table 1. Factors causing the failures of induction motors.

\begin{tabular}{ccccc}
\hline Environmental & Operations & Equipment & Human & Electrical Power \\
& & & & Transients due to: \\
& & & & Short circuit \\
& & & Fluctuations \\
Temperature & Vibration & Aging & Bad selection of electric & Resonance \\
& & & motor & Transfers \\
& & & & Reconnections \\
& & & & Capacitors \\
& & & & Insulation \\
& & & Bad use & Drivers \\
\hline Moisture & Overload & Quality & Voltage drop \\
\hline Rust & Excessive starts & Design defects & Lack of maintenance & Voltage low \\
\hline Ventilation & Alignment & Manufacturing & Improper maintenance or & Voltage unbalance \\
\hline
\end{tabular}




\begin{tabular}{|c|c|c|c|}
\hline Pollution & $\begin{array}{l}\text { Resonance of } \\
\text { the System }\end{array}$ & $\begin{array}{c}\text { Inappropriate or poor } \\
\text { quality parts }\end{array}$ & Harmonics \\
\hline Strange Objects & $\begin{array}{l}\text { Shaft currents } \\
\text { Stator-rotor } \\
\text { Friction } \\
\text { Partial } \\
\text { Discharge (PD) }\end{array}$ & Lubrication & Defective electrical installation \\
\hline
\end{tabular}

Table 2. Mechanical and electrical failures according to the parts of the motor.

\begin{tabular}{|c|c|c|c|c|}
\hline & & ELECTRICAL & MECHANICAL & \\
\hline \multirow{5}{*}{ STATOR } & $\begin{array}{l}\text { Factors for } \\
\text { failures }\end{array}$ & Failures & Failures & $\begin{array}{l}\text { Factors for } \\
\text { failures }\end{array}$ \\
\hline & $\begin{array}{l}\text { Vibration } \\
\text { of coils }\end{array}$ & $\begin{array}{l}\text { Radial and tangential movement } \\
\text { Destruction of winding fastening } \\
\text { Insulation damage } \\
\text { Short circuit }\end{array}$ & $\begin{array}{l}\text { Electromagnetic noise and vibration } \\
\text { Damage to core due to friction with the stator } \\
\text { Destruction of insulation and wedges overheating }\end{array}$ & $\begin{array}{l}\text { Rotor } \\
\text { eccentricity }\end{array}$ \\
\hline & $\begin{array}{l}\text { Insulation } \\
\text { failure }\end{array}$ & $\begin{array}{l}\text { Short circuit between: turns coils } \\
\text { phases phase and ground }\end{array}$ & $\begin{array}{l}\text { Loosening of the core } \\
\text { Loss of interlaminar insulation } \\
\text { Destruction of insulation } \\
\text { Destruction of winding fastening } \\
\text { Decreased performance }\end{array}$ & Overheating \\
\hline & Tracking & $\begin{array}{l}\text { Insulation perforation and } \\
\text { destruction } \\
\text { Circuit formation between } \\
\text { winding and ground } \\
\text { Discharge of currents to ground } \\
\text { Ground fault }\end{array}$ & $\begin{array}{l}\text { Core damage during assembly } \\
\text { Core damage during assembly or rewinding } \\
\text { Applying heat excessive }\end{array}$ & Maintenance \\
\hline & Transients & Insulation destruction & Overheating & $\begin{array}{l}\text { Lack of } \\
\text { ventilation }\end{array}$ \\
\hline \multirow{6}{*}{ ROTOR } & $\begin{array}{l}\text { Vibration } \\
\text { of coils }\end{array}$ & $\begin{array}{l}\text { Radial and tangential movement } \\
\text { Destruction of winding fastening } \\
\text { Insulation damage } \\
\text { Short circuit }\end{array}$ & $\begin{array}{l}\text { Shaft breakage } \\
\text { Bearing, fan and couplings failure } \\
\text { Friction with the stator } \\
\text { Centrifugal and thermal stresses } \\
\text { Stresses in the blades and bars }\end{array}$ & $\begin{array}{l}\text { Dynamic } \\
\text { Failures }\end{array}$ \\
\hline & $\begin{array}{l}\text { Insulation } \\
\text { failure }\end{array}$ & $\begin{array}{l}\text { Short circuit between: turns coils } \\
\text { phases phase and ground }\end{array}$ & $\begin{array}{l}\text { Electromagnetic noise and vibration Damage to } \\
\text { core due to friction with the stator } \\
\text { Bearing failure } \\
\text { Shaft currents } \\
\text { Production of sparks by discharges }\end{array}$ & $\begin{array}{l}\text { Static and } \\
\text { dynamic } \\
\text { eccentricity }\end{array}$ \\
\hline & $\begin{array}{l}\text { Electromag } \\
\text { netic faults }\end{array}$ & $\begin{array}{l}\text { Displacements accompanied by } \\
\text { deflection and stresses of } \\
\text { the bars }\end{array}$ & $\begin{array}{l}\text { Eccentricity, twist, break, residual stresses, } \\
\text { overload, damage during repairs or mounts }\end{array}$ & Shaft \\
\hline & \multirow{3}{*}{$\begin{array}{l}\text { Magnetic } \\
\text { faults }\end{array}$} & \multirow{3}{*}{$\begin{array}{l}\text { Broken bars } \\
\text { Noise } \\
\text { Vibration } \\
\text { Shaft twisting } \\
\text { Bearing failure } \\
\text { Friction with the stator }\end{array}$} & $\begin{array}{l}\text { Loosening core } \\
\text { Loss of interlaminar insulation } \\
\text { Bearing failure }\end{array}$ & Overheating \\
\hline & & & Overheating & $\begin{array}{l}\text { Lack of } \\
\text { ventilation }\end{array}$ \\
\hline & & & $\begin{array}{l}\text { Eccentricity electromagnetic noise and vibration } \\
\text { Damage to core due to friction with the stator } \\
\text { Shaft currents } \\
\text { Production of sparks by discharges }\end{array}$ & Bearing \\
\hline
\end{tabular}


Table 3. Effects according to the type of efforts to which the parts of an induction motor are subjected.

\begin{tabular}{|c|c|c|c|c|c|c|c|c|c|c|c|}
\hline \multicolumn{12}{|c|}{ Stresses } \\
\hline & & Mechanical & Electrical & Magnetic & Thermal & Environmental & Residual & Dynamic & $\begin{array}{l}\text { Vibration or } \\
\text { Shakes }\end{array}$ & $\begin{array}{c}\text { Dynamic } \\
\text { and Static } \\
\text { Charges }\end{array}$ & Others \\
\hline & \multirow{5}{*}{$\begin{array}{c}\text { Stator } \\
\text { Winding }\end{array}$} & $\begin{array}{l}\text { Friction between } \\
\text { coils }\end{array}$ & $\begin{array}{l}\text { Degradation of } \\
\text { the dielectric }\end{array}$ & & Aging & Humidity & & & & & \\
\hline & & Rotor strikes & Crown effect & & $\begin{array}{c}\text { Voltage } \\
\text { variation }\end{array}$ & Abrasion & & & & & \\
\hline & & Rotor defects & Transient & & Load & Chemicals & & & & & \\
\hline & & Impact of objects & & & Ventilation & Ventilation & & & & & \\
\hline & & & & & Environment & Temperature & & & & & \\
\hline \multirow{6}{*}{ Effects } & \multirow{6}{*}{ Rotor } & $\begin{array}{l}\text { Cast Iron } \\
\text { Impurities }\end{array}$ & & Noise & $\begin{array}{l}\text { Thermal } \\
\text { overload }\end{array}$ & Humidity & $\begin{array}{l}\text { Concentration } \\
\text { of stresses }\end{array}$ & Vibration & & & $\begin{array}{l}\text { Poor design or } \\
\text { Manufacturing } \\
\text { defects }\end{array}$ \\
\hline & & $\begin{array}{l}\text { Destruction of } \\
\text { sheets }\end{array}$ & & $\begin{array}{l}\text { Circulation of } \\
\text { currents }\end{array}$ & $\begin{array}{l}\text { Thermal } \\
\text { imbalance }\end{array}$ & Abrasion & & Friction & & & Transient torques \\
\hline & & Fatigue & & Vibrations & $\begin{array}{c}\text { Excessive rotor } \\
\text { losses }\end{array}$ & Chemicals & $\begin{array}{l}\text { Unequal } \\
\text { stresses on } \\
\text { bars }\end{array}$ & $\begin{array}{l}\text { High } \\
\text { speeds }\end{array}$ & & & Core or bars wear \\
\hline & & Misaligned & & $\begin{array}{c}\text { Core } \\
\text { saturation }\end{array}$ & Sparks & Poor ventilation & & $\begin{array}{l}\text { Cyclic } \\
\text { stresses }\end{array}$ & & & $\begin{array}{c}\text { Rotation direction } \\
\text { wrong }\end{array}$ \\
\hline & & $\begin{array}{c}\text { Material } \\
\text { deviations }\end{array}$ & & & Hot spots & Overheating & & $\begin{array}{l}\text { Centrifugal } \\
\text { forces }\end{array}$ & & & \\
\hline & & Incorrect settings & & & & Pollution & & & & & \\
\hline \multirow{7}{*}{ Effects } & \multirow{4}{*}{ Bearings } & Loss of slack & $\begin{array}{l}\text { Misaligned } \\
\text { rotor }\end{array}$ & & Friction & Condensation & & & Vibration & Radial & \\
\hline & & Misaligned & $\begin{array}{l}\text { Electrostatic } \\
\text { charge }\end{array}$ & & Lubrication & $\begin{array}{l}\text { Materials } \\
\text { foreign }\end{array}$ & & & & Axial & \\
\hline & & $\begin{array}{l}\text { Bearing housing } \\
\quad \text { wear }\end{array}$ & $\begin{array}{l}\text { Electrostatic } \\
\text { coupling }\end{array}$ & & Environment & Overheating & & & $\begin{array}{l}\text { Coupling } \\
\text { equipment }\end{array}$ & Preload & \\
\hline & & & $\begin{array}{l}\text { Frequency } \\
\text { variations }\end{array}$ & & & Ventilation lack & & & & & \\
\hline & \multirow{3}{*}{ Shaft } & $\begin{array}{l}\text { Overload and } \\
\text { flexion }\end{array}$ & & Lateral loads & $\begin{array}{c}\text { Temperature } \\
\text { gradients }\end{array}$ & Corrosion & & Cyclic loads & & & $\begin{array}{l}\text { Manufacturing } \\
\text { processes }\end{array}$ \\
\hline & & Torsional load & & & & Moisture & & Shakes & & & \\
\hline & & Axial loads & & Gap & & $\begin{array}{l}\text { Erosion } \\
\text { Wear }\end{array}$ & & & & & Repair processes \\
\hline
\end{tabular}


Table 4. Failures according to the engine part (\%).

\begin{tabular}{|c|c|c|c|c|c|c|c|c|c|c|c|}
\hline \multirow{2}{*}{ REFERENCES } & \multirow{2}{*}{ [21] } & \multirow{2}{*}{ [23] } & \multicolumn{3}{|c|}{ [24] } & \multirow{2}{*}{ [25] } & \multirow{2}{*}{ [26] } & \multirow{2}{*}{ [22] } & \multirow{2}{*}{ [27] } & \multirow{2}{*}{ [28] } & \multirow{2}{*}{ [29] } \\
\hline & & & IEEE-IAS & EPRI & Allianz & & & & & & \\
\hline Bearings & 41 & 69 & 44 & 41 & 13 & $40-50$ & 44 & 51 & 40 & $40-50$ & 42 \\
\hline Stator & 23 & 21 & 26 & 36 & 66 & $28-43$ & & 26 & 38 & $30-40$ & 31 \\
\hline Inter-turn short circuits & & & & & & & 26 & & & & \\
\hline Rotor & 10 & & 8 & 9 & 13 & $5-10$ & & & 10 & & \\
\hline Broken bars/end ring & & 7 & & & & & 8 & 5 & & $5-10$ & 9 \\
\hline Shaft/coupling & & 3 & & & & & & 2 & & & \\
\hline Unknown causes & & & & & & & & 10 & & & \\
\hline External causes & & & & & & & & 16 & & & \\
\hline Others & 12 & & 22 & 14 & 8 & 12 & 22 & & 12 & & 12 \\
\hline
\end{tabular}

Table 5. Failures according to the severity level.

\begin{tabular}{cc}
\hline Failure & $\%$ \\
\hline Failure Initiator & \\
\hline Transient overvoltage & 1.5 \\
Overheating & 3.2 \\
Other insulation breakdown & 12.3 \\
Mechanical breakage & 33.1 \\
Electrical fault or malfunction & 7.6 \\
Stalled motor & 0.9 \\
Other & 31.4 \\
\hline Failure Contributor & \\
\hline Persistent overloading & 4.2 \\
High ambient temperature & 3.0 \\
Abnormal moisture & 5.8 \\
Abnormal voltage & 1.5 \\
Abnormal frequency & 0.6 \\
High vibration & 15.5 \\
Aggressive chemicals & 4.2 \\
Poor lubrication & 15.2 \\
Poor ventilation or cooling & 3.9 \\
Normal deterioration from age & 26.4 \\
Other & 19.7 \\
\hline Underlying Failure Cause & \\
\hline Defective component & 20.1 \\
Poor installation/testing & 12,9 \\
Inadequate maintenance & 21.4 \\
Improper operation & 3.6 \\
Improper handling/shipping & 0.6 \\
Inadequate physical protection & 6.1 \\
Inadequate electrical protection & 5.8 \\
Personnel error & 6.8 \\
Outside agency other than & 3.9 \\
personnel & 4.9 \\
Ootor-driven equipment mismatch & 13.9 \\
\hline
\end{tabular}


Table 6. Failures according to the electric motor parts.

\begin{tabular}{cc}
\hline Bearing Related & $\%$ \\
\hline Sleeve bearings & 16 \\
Antifriction bearings & 8 \\
Seals & 6 \\
Thrust bearing & 5 \\
Oil leakage & 3 \\
Other & 0.9 \\
Total & 41 \\
\hline Stator Related & \\
\hline Ground insulation & 23 \\
Turn insulation & 4 \\
Bracing & 3 \\
Wedges & 1 \\
Frame & 1 \\
Core & 1 \\
Other & 4 \\
Total & 37 \\
\hline Rotor Related & \\
\hline Cage & 5 \\
Shaft & 2 \\
Core & 1 \\
Other & 2 \\
Total & 10 \\
\hline &
\end{tabular}

\subsection{Maintenance Strategies}

According to Das et al. [30], the application of strategies for the monitoring, detection and diagnosis of failures can be traced back to 1931 when Walter Shewhar used the control charts to determine if a process was under statistical control. At the end of the nineteenth century, the demand for industrialized products exceeded the supply, so companies focused on quantity rather than quality. In these conditions, the early technological development gave rise to a corrective type of maintenance applied to electric motors. That is, repair work was done when the damage became very noticeable or the electrical motor was completely damaged, focusing on changing bearings, repairing cashiers, cleaning, increasing insulation and rewinding.

The industrial development and the increased competition made that competitiveness a key factor in the success of any company. Production stopped focusing on quantity to focus on quality and the customers, which meant delivering flawless products with warranties and on time. Unexpected production stoppages could not be allowed due to all the internal costs i.e., bad reputation, customer dissatisfaction and losses, and costs related specifically to the repair or replacement of electric motors. The competitive and changing environment in which companies were found motivated them to develop and apply new methods to improve the reliability of the equipment that was part of the production system within which electric motors have always constituted one of the most important parts. Once again, scientific and technological progress made it possible to develop and implement maintenance techniques to reduce unforeseen interruptions due to sudden engine failures.

Maintenance operations are characterized by their complexity since they can involve a large number of variables, and some of them are difficult to predict and have high cost and risk; these factors require the following:

- Careful planning and control.

- Optimization of the resources.

- Adherence to safe working procedures. 
- Continuous research and development of integrated management tools.

If the decision to provide maintenance over the life of the equipment has been made, several strategies have been designed over time. These can be preventive, diagnostic (expert system), Total Productive Maintenance (TPM), proactive and predictive [27,31]. Each of these techniques is characterized by the strategies used and the associated costs, such as financial, quality of service, administrative, unproductive times, skilled labor, tools, applied technology, logistics and spare parts.

Although preventive and corrective maintenance have traditionally been used, due to technological development, reliability and cost reduction, the trend is changing. Predictive maintenance for the early detection of both mechanical and electrical failures based on the study of frequency spectra using artificial intelligence techniques has been implemented more frequently, Aroui et al. [32]. According to the same author, some of the advantages of predictive maintenance are the following:

- Reduction of repair costs caused by a breakdown.

- Increased availability or useful life of the machines.

- $\quad$ More targeted planning of the maintenance work.

- Better protection of industrial equipment, since it takes into account the state of the components to prevent failure thereof.

- Detect anomalies immediately, at the control or diagnostic center.

- $\quad$ Record the behavior of the machine.

- Collect data in extreme climate situations.

- Minimize unnecessary maintenance actions.

- Allows the remote and automatic monitoring of the components and provides abundant information regarding the operation thereof.

According to [31], among the different types of maintenance, the predictive approach is characterized by the implementation of Computerized Maintenance Systems (CMMS); investment in staff training; technologies for the monitoring of conditions (Conditions Monitoring (CM)) and Centered Reliability Maintenance (CRM); as well as failure analysis, statistical modeling, critical analysis and failure effects. The maintenance approach based on expert systems is highlighted by the use of technologies of remote and automatic diagnostics. According to Thomson and Fenger [33], these strategies are widely used in the industry and one of the main features is the continuous monitoring of electrical equipment to extract timely and early information associated with different types of failures.

In what refers strictly to the part corresponding to the Process to Monitor and Detect the Failures (PMFD) of electric motors, according to [30], the techniques employed depending on the diagnostic strategies are classified according to Table 7, while the advantages and disadvantages of each of the factors that should be considered when developing a PMFD are included in Table 8. However, as indicated by [30], "The review reveals that there is no single strategy that can address all aspects related to process monitoring and fault detection efficiently, and there is a need to mesh the different techniques from various PMFD strategies to devise a more efficient PMFD strategy. Greater emphasis needs to be given to the development of PMFD strategies based on amalgamation of two or more techniques in order to deal with complex ever-evolving manufacturing processes." 
Table 7. Techniques applied to the strategies of monitoring and fault detection.

\begin{tabular}{clll}
\hline $\begin{array}{c}\text { Applied } \\
\text { Techniques }\end{array}$ & \multicolumn{1}{c}{$\begin{array}{c}\text { (Data-Based Approach) } \\
\text { Data-Driven Techniques }\end{array}$} & $\begin{array}{c}\text { Prior Knowledge-Based Techniques } \\
\text { (Model-Based Approach) }\end{array}$ & Hybrid Models \\
\hline \multirow{3}{*}{ Fundamentals } & $\begin{array}{l}\text { Empirical models constructed } \\
\text { primarily from the process } \\
\text { history data }\end{array}$ & $\begin{array}{l}\text { Relies on an explicit model of the process } \\
\text { primarily based on first principles, } \\
\text { input-output or state space models }\end{array}$ & \\
\hline & $\begin{array}{l}\text { Statistical Techniques } \\
\text { Artificial Intelligence }\end{array}$ & Parameter-based estimation method & $\begin{array}{l}\text { Amalgamation of } \\
\text { the data-based } \\
\text { and model-based } \\
\text { approaches }\end{array}$ \\
\cline { 2 - 4 } Classification & $\begin{array}{l}\text { Technique based (artificial } \\
\text { neural network and } \\
\text { fuzzy logic) }\end{array}$ & Observer-based method & \\
\cline { 2 - 4 } & $\begin{array}{l}\text { Artificial Neural Network } \\
\text { (ANN)-fuzzy logic }\end{array}$ & Based on parity relations & \\
\hline
\end{tabular}

Table 8. Comparison between strategies of the monitoring process and fault diagnosis.

\begin{tabular}{|c|c|c|c|c|c|}
\hline \multirow[b]{2}{*}{ Characteristics } & \multicolumn{2}{|c|}{ Data-Based Approach } & \multicolumn{3}{|c|}{ Prior Knowledge-Based or Model-Based Approach } \\
\hline & Statistical Techniques & AI & Parameter Estimation & $\begin{array}{l}\text { Observer } \\
\text { Based }\end{array}$ & $\begin{array}{c}\text { Parity } \\
\text { Relations }\end{array}$ \\
\hline $\begin{array}{c}\text { Ease of } \\
\text { development }\end{array}$ & Easy & Easy & Relatively tough & Tough & Tough \\
\hline $\begin{array}{l}\text { Diagnostic } \\
\text { ability }\end{array}$ & Satisfactory & Very Good & Good & Good & Good \\
\hline Detection speed & Quick & Quick & $\begin{array}{c}\text { Quick for abrupt faults, } \\
\text { but relatively slow for } \\
\text { developing faults }\end{array}$ & $\begin{array}{l}\text { Quick for } \\
\text { abrupt } \\
\text { faults }\end{array}$ & $\begin{array}{l}\text { Quick for } \\
\text { abrupt } \\
\text { faults }\end{array}$ \\
\hline $\begin{array}{c}\text { Robustness to } \\
\text { noise }\end{array}$ & Good & Very good & Poor & Poor & Poor \\
\hline $\begin{array}{c}\text { Generalization } \\
\text { capability }\end{array}$ & Poor & Poor & Good & Good & Good \\
\hline $\begin{array}{l}\text { Handling of } \\
\text { nonlinearity }\end{array}$ & Good & Excellent & Satisfactory & Satisfactory & Satisfactory \\
\hline $\begin{array}{l}\text { Failure types } \\
\text { addressed }\end{array}$ & $\begin{array}{l}\text { Mainly process } \\
\text { component or } \\
\text { equipment failures }\end{array}$ & & $\begin{array}{l}\text { Mainly actuator and } \\
\text { sensor failures }\end{array}$ & & \\
\hline $\begin{array}{c}\text { Industrial } \\
\text { applicability }\end{array}$ & $\begin{array}{l}\text { Predominantly process } \\
\text { industries }\end{array}$ & $\begin{array}{c}\text { Varied } \\
\text { applications }\end{array}$ & $\begin{array}{c}\text { Predominantly } \\
\text { mechanical and airspace } \\
\text { industries }\end{array}$ & & \\
\hline
\end{tabular}

\section{Maintenance of Electric Induction Motors}

At first, the protection of induction motors was limited to the use of devices against overcurrent, overvoltage and ground faults, Nandi [34]. However, as soon as diverse applications began to be used extensively, where conversion between electrical and mechanical energy was necessary, the need to repair, diagnose and predict the failures associated with this type of machine to ensure the continuity of operations also appeared. The problems associated with the unexpected exit of the electric motor, including repair or replacement costs, stopping production processes with consequent economic losses, the reputation of the company, and customer satisfaction, motivated the continuous evolution of maintenance strategies in parallel to the constant improvement in the design of the motors. This evolution started with the corrective model and then extended to the programmed and predictive model, until the present time that the philosophy of Total Productive Maintenance (TPM) is used.

Regarding the operative part, since the electric motors began to be used, the maintenance of these equipment has evolved from the visual inspection, empirical analysis, repairs in the workshops, use of invasive diagnostic techniques (test of high potential, index of Polarization), non-invasive techniques that are based on the acquisition, treatment and analysis of the spectrum of signals, to the present day where the results of the mentioned techniques are used to feed programs based on Artificial Intelligence (AI) technique such as Artificial Neural Networks (ANN), Fuzzy Logic and Support Vector Machines (SVM), all of which attempt to cover as many potential causes of 
breakdowns as possible, minimize uncertainty, and provide reliable diagnostics to ensure engine life in demanding environments and ensure the profitability of both the equipment manufacturer and the customer. Several invasive and non-invasive maintenance techniques have been designed, which, according to Aroui et al. [32], may include:

- Electromagnetic field monitoring, search coils, and coils wound around motor shafts (axial flux related detection).

- Temperature measurements.

- Infrared recognition.

- Radio Frequency (RF) emissions monitoring.

- Noise and vibration measurements and monitoring.

- Chemical analysis.

- Acoustic measurements.

- Motor Current Signature Analysis (MCSA).

\subsection{Maintenance through Invasive Techniques}

Initially, besides the analysis in the time domain, part of the techniques developed with the purpose of knowing the state of the electric motors are what are known as invasive tests, so called because in order to realize them, it is necessary to apply a signal of voltage or current to the motor. In this type of tests, one of the key indicators of the winding state is the insulation of turns, coils and phases and the insulation between the latter and the ground. According to Peña et al. [35], the tests for measuring insulation are divided into analytical tests and by Type. Analytical tests measure insulation from the ground and include reading, polarity index and stepped voltage. Type tests include high potential (HiPot) and comparison of voltage impulses. The invasive tests used to test a new or repaired motor and to diagnose its conditions are described in the IEEE 1415 standard, [19]; see Table 9.

Despite the technological advances and benefits of the invasive tests, they have the disadvantages of stressing the insulation and windings, require expensive equipment, can be dangerous for the people who perform them and must be done when the machine is not operating, In some cases it is required to disassemble the motor (this is critical in large machines) and specific tests must be performed for each type of fault.

Table 9. Invasive tests.

\begin{tabular}{|c|c|c|c|}
\hline Test & Description & Effectiveness & Test Precautions/Considerations \\
\hline AC high potential & $\begin{array}{l}\text { Overvoltage test applied from } \\
\text { conductor-to-ground. }\end{array}$ & $\begin{array}{l}\text { Pass/Fail Test; not effective for } \\
\text { trending. }\end{array}$ & Potentially destructive. \\
\hline Capacitance & $\begin{array}{l}\text { AC test to measure insulation } \\
\text { capacitance line-to-ground. }\end{array}$ & $\begin{array}{l}\text { Effective in manufacturing; } \\
\text { possibly effective for trending. }\end{array}$ & $\begin{array}{l}\text { Effective on single coils during } \\
\text { manufacturing of medium-voltage } \\
\text { machines. }\end{array}$ \\
\hline Core loss (loop) & $\begin{array}{l}\text { Test for shorted stator core } \\
\text { laminations. }\end{array}$ & $\begin{array}{l}\text { Pass/Fail Test; not typically } \\
\text { effective for trending, } \\
\text { although may be used for } \\
\text { trending under controlled } \\
\text { conditions. }\end{array}$ & $\begin{array}{l}\text { Be prepared to stop test abruptly if } \\
\text { core damage is suspected. }\end{array}$ \\
\hline DC high potential & $\begin{array}{l}\text { Overvoltage test applied line } \\
\text { to ground test, measures } \\
\text { leakage current plus charging } \\
\text { current. }\end{array}$ & $\begin{array}{l}\text { Effective for trending and as } \\
\text { pass/fail. }\end{array}$ & $\begin{array}{l}\text { DC high potential test should only be } \\
\text { undertaken after passing the } \\
\text { PI test. }\end{array}$ \\
\hline $\begin{array}{l}\text { Dielectric } \\
\text { absorption }\end{array}$ & $\begin{array}{l}\text { Ratio of the } 60 \text {-s IR reading to } \\
\text { the } 30 \text {-s IR reading. }\end{array}$ & Effective for trending & \\
\hline $\begin{array}{l}\text { Dissipation factor } \\
\text { and power factor }\end{array}$ & $\begin{array}{l}\text { AC test measuring } \\
\text { dissipation-capacitance } \\
\text { line-to-ground. }\end{array}$ & $\begin{array}{l}\text { Effective on single coils during } \\
\text { manufacturing of } \\
\text { medium-voltage machines; } \\
\text { possibly effective for trending. }\end{array}$ & \\
\hline Grease analysis & $\begin{array}{l}\text { Appearance, smell, grit, } \\
\text { content of grease sample } \\
\text { grease lubricated machine } \\
\text { bearings. }\end{array}$ & Effective for trending. & \\
\hline
\end{tabular}




\begin{tabular}{|c|c|c|c|}
\hline Growler & $\begin{array}{l}\text { Tests of rotor core and squirrel } \\
\text { cage of disassembled machine } \\
\text { by introducing an external } \\
\text { magnetic field, and monitoring } \\
\text { temperatures, magnetic } \\
\text { patterns or current patterns of } \\
\text { the rotor. }\end{array}$ & $\begin{array}{l}\text { Pass/fail test; not effective for } \\
\text { trending. }\end{array}$ & \\
\hline $\begin{array}{l}\text { Insulation } \\
\text { resistance }\end{array}$ & $\begin{array}{l}\text { Measures resistance of } \\
\text { insulation between conductor } \\
\text { and ground. }\end{array}$ & Effective for trending. & $\begin{array}{l}\text { Temperature correction required for } \\
\text { trending. Adequate scale range } \\
\text { required. }\end{array}$ \\
\hline Oil analysis & $\begin{array}{l}\text { Analysis of oil for lubricant } \\
\text { characteristics and foreign } \\
\text { particle concentration for } \\
\text { oil-lubricated } \\
\text { machine bearings. }\end{array}$ & Effective for trending. & \\
\hline Partial discharge & $\begin{array}{l}\text { AC test that measures partial } \\
\text { discharge (corona) } \\
\text { line-to-ground. }\end{array}$ & $\begin{array}{l}\text { Requires experienced } \\
\text { operator; effective for trending } \\
\text { with some technologies. }\end{array}$ & \\
\hline Phase angle & $\begin{array}{l}\text { Timed measurement of } \\
\text { voltage and current angle } \\
\text { in degrees. }\end{array}$ & Effective for trending. & \\
\hline $\begin{array}{l}\text { Phase balance } \\
\text { (Inductance and } \\
\text { Impedance) }\end{array}$ & $\begin{array}{l}\text { AC frequency test to measure } \\
\text { stator line-to-line inductance } \\
\text { or impedance balance. }\end{array}$ & Effective for trending. & $\begin{array}{l}\text { Correct for winding temperature and } \\
\text { rotor position. }\end{array}$ \\
\hline $\begin{array}{l}\text { Polarization } \\
\text { index }\end{array}$ & $\begin{array}{l}\text { Ratio of ten-minute IR to } \\
\text { one-minute IR. }\end{array}$ & Effective for trending. & $\begin{array}{l}\text { Should have adequate scale range. } \\
\text { Note: form-wound coils only. }\end{array}$ \\
\hline $\begin{array}{l}\text { Single-phase } \\
\text { rotor test }\end{array}$ & $\begin{array}{l}\text { Monitors the AC current level } \\
\text { while the machine is single- } \\
\text { phased at lower voltage level, } \\
\text { while the shaft is } \\
\text { rotated manually. }\end{array}$ & Pass/fail. & $\begin{array}{l}\text { WARNING: possible hazard to } \\
\text { operator; risk of single-phase start. }\end{array}$ \\
\hline
\end{tabular}

\subsection{Maintenance through Non-Invasive Techniques}

The disadvantages of invasive testing and the need to find alternative and complementary methods to monitor, detect and diagnose a variety of failures in a precise, simple and economical way without putting people at risk or stopping operations resulted in a significant amount of research. These studies were conducted due to the progress in the development of new mathematical models to describe and predict the behavior of the electric motor, electronic analog and digital, hardware and software development in the field of communications, specifically related to the generation, transmission, acquisition, treatment and monitoring of signals.

Signals from stator currents, magnetic field, vibrations, noise and temperature contain valuable information. The non-invasive techniques are based on several mathematical models that allow one to treat, decompose and analyze the spectrum of signals to identify irregularities that are associated with the failures that can occur in the induction motor while it operates normally without leaving the production line, Drozdowski and Duda [36]. The same authors mentions that the identification of the faults has allowed for the creation of databases that can be used to train intelligent systems capable of autonomously detecting any deviation from the normal operation of the equipment and mainly at an early stage.

According to Narwade et al. [37], one of the most popular and accurate techniques for detecting faults in induction motors is currently the MCSA. The monitoring, detection and diagnosis of the engine conditions can be done while the machine is operating by using the current and voltage transformers used in the protection system. MCSA includes parametric analysis methods (signal analysis as a function of time, frequency spectrum), non-parametric methods (techniques such as Fast Fourier Transform) and high-resolution or sub-space methods (these obtain the autocorrelation matrix, and their eigenvalues separate the subspaces corresponding to the signal and noise). When the signal is not stationary, diagnostic techniques are mainly based on higher order spectral analysis (time-frequency), such as bispectrum and trispectrum, and higher order statistical methods to obtain the density of the frequency spectrum [34,38]. 
Each type of failure that occurs in the induction motors will specifically affect the signal that is being analyzed. For this reason, the central objective of MCSA is to determine the differences in signal patterns (spectrum) of an engine in good condition and another that features a failure. In this way, it is possible to monitor and diagnose failures associated with the rotor (broken bars, eccentricity, bearings and shaft), bearing problems and stator short circuits. According to Thomson and Fenger [33], to choose the appropriate monitoring technique in industrial environments, it must be taken into account that, to trust that the diagnosis is correct, to quantify the severity of the problem, to determine the origin of the failure, and to give a pre-diagnosis of the remaining operation time, it must be verified that the sensor is reliable and non-invasive. Moreover, due to the effect that this may have on the diagnosis, the design of the machine, the power range, the coupled mechanical components, the conditions and the load characteristics should be considered. Bellini et al. [23] classified the procedures using MCSA according to Figure 3.

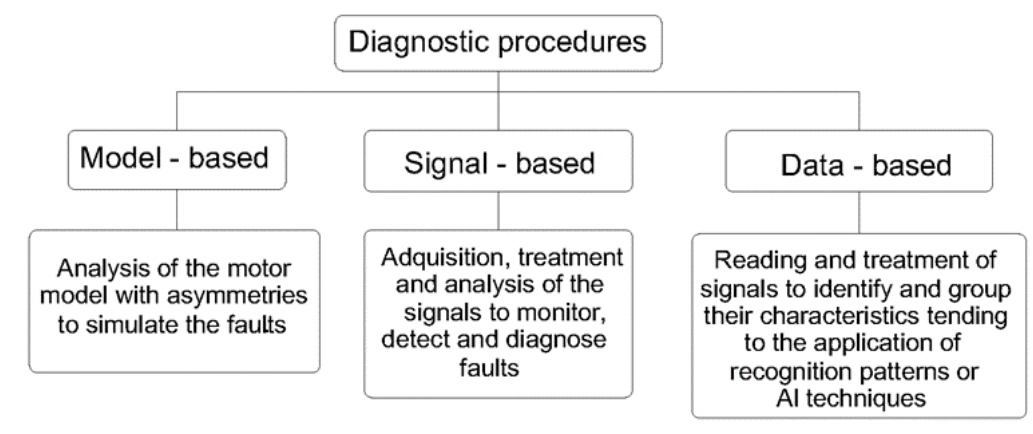

Figure 3. Methods of analysis using Motor Current Signature Analysis (MCSA), as shown in [23].

In general terms, it is known that the asymmetries will be reflected in the motor signals in the form of sidebands distributed with a certain uniformity around the main component. However, this spacing can be altered due to factors such as load variation, which should be kept in mind when making a diagnosis. Moreover, the assumption of uniformity may be valid for the model of one machine but not for others [23]. In many cases, the noise or the applied technique makes it difficult to distinguish the failures, so it is necessary to use an adequate technique of decomposition of the signal to obtain the instantaneous frequencies. According to Clemente [39], the disadvantages of the analysis methods of non-parametric signals using the Fourier transform are bandwidth limitation, distortion due to low sampling speed (aliasing), distortion due to finite signal length of the signal (leakage), the Picket fence effect, and speed variations. When using the Fourier analysis, the results obtained include the unwanted part of the signal (noise) due to these factors. This often occurs in the transient operating states, such as the starters of induction motors.

As an alternative to these inconveniences, one of the methods for decomposing the signal is through Empirical Mode Decomposition (EMD), thus obtaining a set of Intrinsic Mode Functions (IMFs) of different frequencies containing the sidebands. The next step is to get the amplitude and frequency of each IMF using the Hilbert Transform (HT); for this reason, this method is called the Hilbert-Huang Transform, Batista et al. [26]. Figure 4 is an example of the results obtained. 


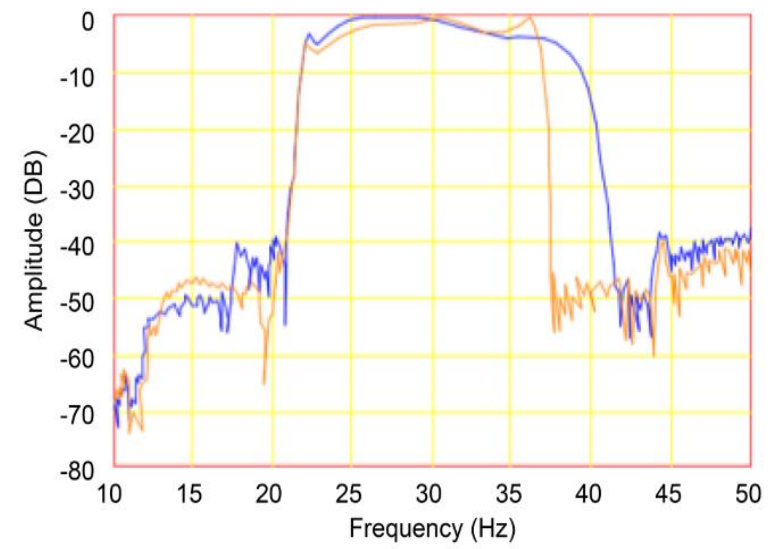

(a)

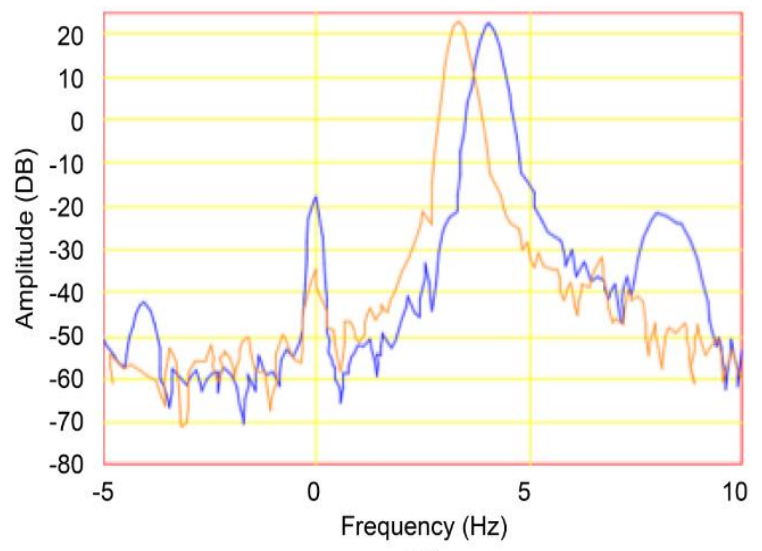

(b)

Figure 4. Spectrum of the phase current signal of a motor. (a) Fast Fourier Transform (FFT); (b) Demodulation. The red line indicates health status, while the blue line indicates failure, as shown in [40]. Reproduced with permission from IEEE, 2017

According to Stranneby and Walker [17], several methods of treatment and filtering (Infinite Impulse Response (IIR), Finite Impulse Response (FIR), Low Pass, high Pass, Band Pass, Stop Butterworth, Chebysheff, Eliptical or Cauer, Bessel and Total Pass Filters) of the signal have also been developed, which serve as alternatives to overcome the inconveniences that mean the elimination of unwanted components that hinder the correct diagnosis of the failures in the motor. A sample of the techniques used to treat the signal is included in Figure 5, [37,39]. Each method has its advantages and disadvantages, thus motivating the continuous development of new mathematical models to ensure the following, according to Kia et al. [38]:

- Reducing computation time.

- Saving memory space.

- Security in the specified frequency range.

The emergence of the drivers signified a great advance in the operation and control of electric motors, but the harmonics that these generate posed a new challenge in the development of methodologies for the monitoring, detection, and diagnosis of the failures in the machines that worked with converters, Bellini [23]. According to Duque-Pérez et al. [41], to design a method that is valid for any power source and frequency of operation, it is necessary to consider and identify the influence of the different operating conditions. For this, [41] proposes an experimental study, a statistical analysis based on an additive model that allows for recognition of the effect the power supply has on the field harmonics, the same ones that will be affected by any failure in the motor. This method can detect the broken bars of a motor when it is fed in five different ways, directly to the power supply network and through four converters of various brands and models. García-Escudero et al. [42] also present a method based on statistical techniques (Control Quality) to determine the early failures in inverter-powered motors. According to the authors, this method for running engines is a robust proposal for the detection of broken bars, mixed eccentricity, and bearings.

When motors work with AC variable speed drivers, another diagnostic alternative is based on Park's vector. According to Henao et al. [40], the dependence of the load and the sensitivity to the variations of velocity that were the major disadvantages in carrying out the diagnosis have been overcome by recent techniques based on the approach of Park's vector. The same author mentions four techniques that have demonstrated high effectiveness even for low loads and that are simple to implement, operate independently, have low computational demand and limit the need for hardware. These methods are Errors of Normalized Currents Average Absolute Values (ENCAAVs), Current Park's Vector Phase and Currents Polarity (CPVPCP), Normalized Currents Average Values (NCAVs) and Normalized Reference Current Errors (NRCEs). 


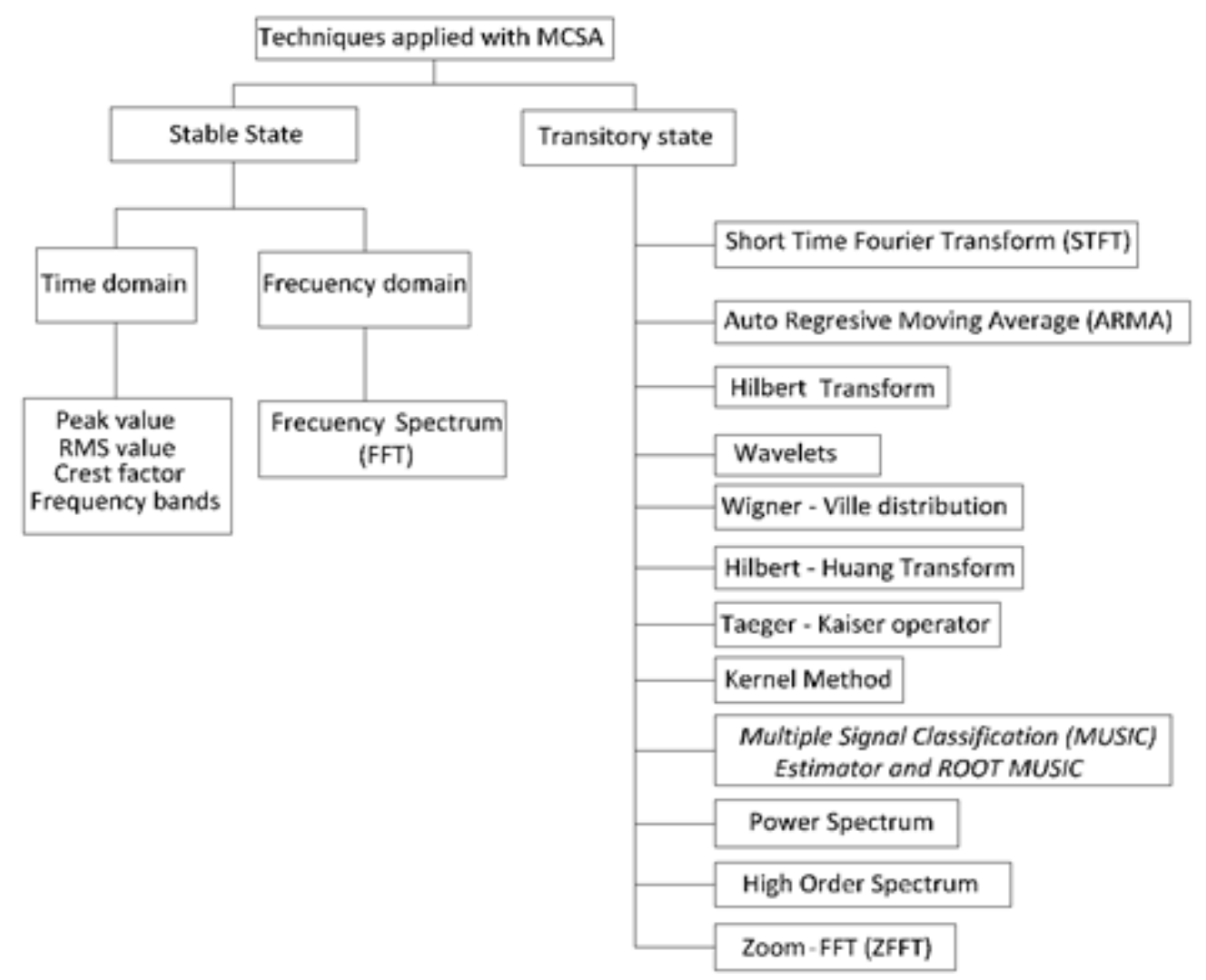

Figure 5. Methods of treatment and analysis of the signals, as shown in [37,39].

Referring to techniques for the forecasting of the electrical energy demand, Hernández et al. [43] state that, in recent times, thanks to the development of computers and their ability to solve complex problems, there has been a proliferation and evolution of techniques and systems. A similar situation has occurred with the field related to the monitoring, detection, diagnosis and prediction of failures of electric induction motors, giving rise to a significant number of publications in this field, and since it would be complicated to analyze them all, this research is limited to the fundamentals. Table 10 shows a matrix relationship among the failures, applied techniques and investigations conducted. 
Table 10. Publications according to applied methodology and detected failures.

\begin{tabular}{|c|c|c|c|c|c|c|c|c|c|}
\hline & & Broken Bars & Bearings & Eccentricity & $\begin{array}{c}\text { Unbalance } \\
\text { Shaft }\end{array}$ & $\begin{array}{c}\text { Winding } \\
\text { Short }\end{array}$ & $\begin{array}{c}\text { Rotor } \\
\text { Asymmetry }\end{array}$ & $\begin{array}{c}\text { Voltage } \\
\text { Unbalance }\end{array}$ & $\begin{array}{c}\text { Insulation } \\
\text { between Turns }\end{array}$ \\
\hline Signal & Applied Technique & & & & & & & & \\
\hline \multirow{9}{*}{ Current } & Fast Fourier Transform (FFT) & {$[23,24,34,37,44,45]$} & {$[23,24,37,40]$} & {$[24,31,46]$} & & {$[23,24,33]$} & & {$[37]$} & [47] \\
\hline & Short Time Fast Fourier Transform (STFT) & [48] & & [48] & & & & [48] & \\
\hline & Music, Root music & {$[25,37,49]$} & {$[23,25,49]$} & [23] & [49] & & & [25] & \\
\hline & Wavelets & [50] & [51] & & & & & & \\
\hline & $\begin{array}{l}\text { Time Frequency Representation (TFR) } \\
\text { Mahalanobis Distance }\end{array}$ & [18] & [18] & & & [18] & & & \\
\hline & $\begin{array}{l}\text { Wavelet Transform Decomposition Wavelet } \\
\text { Power Spectral Density }\end{array}$ & [52] & & & & [52] & & & \\
\hline & $\begin{array}{l}\text { Park's Vector Square Modulus (PVSM) and } \\
\text { Park-Hilbert (P-H) }\end{array}$ & [53] & & [54] & & [53] & & & \\
\hline & Input Power & [12] & {$[12]$} & [12] & & & [12] & & \\
\hline & Finite Element & & & [55] & & & & & \\
\hline \multirow{2}{*}{$\begin{array}{l}\text { Current } \\
\text { (drivers) }\end{array}$} & Statistical analysis based on additive model & {$[40,41]$} & [42] & [42] & & & & & \\
\hline & Wavelet Packet Decomposition (WPD) & [56] & & [56] & & & [56] & & \\
\hline $\begin{array}{l}\text { External radial } \\
\text { flux } \\
\end{array}$ & $\begin{array}{l}\text { Empirical Demodulation (ED) Hilbert } \\
\text { Transform (HT) }\end{array}$ & {$[40,44]$} & & & & {$[27,40]$} & & [27] & \\
\hline \multirow{7}{*}{ Vibration } & MCSA (FFT) & [45] & {$[24,47,49]$} & [49] & & {$[27,53]$} & & {$[27,53]$} & \\
\hline & Fault Frequency Highlighting (FFH) & & & & & [53] & & [53] & \\
\hline & $\begin{array}{l}\text { Gaussian Mixture Models and Bayesian } \\
\text { classification }\end{array}$ & & [57] & & & & & & \\
\hline & Wavelet (Gaussian envelope oscillation) & [58] & [58] & & [58] & & [58] & & \\
\hline & $\begin{array}{l}\text { Empirical Mode Decomposition (EMD) Time } \\
\text { series trending for condition assessment and } \\
\text { prognostics }\end{array}$ & & [59] & & & & & & \\
\hline & $\begin{array}{l}\text { Envelope Order Spectrum (EOS) tacholess } \\
\text { envelope order analysis technique }\end{array}$ & & {$[60]$} & & & & & & \\
\hline & Higher Order Spectra (HOS) & [61] & & [61] & & [61] & & & \\
\hline $\begin{array}{l}\text { Zero sequence } \\
\text { voltage }\end{array}$ & & {$[33,49]$} & & [36] & & & [36] & & {$[62]$} \\
\hline Thermal & & & {$[24]$} & & & & {$[24]$} & & \\
\hline Acoustic & & & [24] & & & & & & \\
\hline $\begin{array}{c}\text { Torque } \\
\text { variations }\end{array}$ & & [44] & & & & & & & \\
\hline $\begin{array}{l}\text { Equivalent } \\
\text { circuit }\end{array}$ & & [63] & & & & & & & \\
\hline
\end{tabular}




\subsection{Software and Hardware Used for Monitoring, Detection, and Diagnosis of Failures}

Despite the complexity of the physical concepts and mathematical models developed and utilized for the diagnosis of electric motor failures, the software and hardware tools used today in each of the stages of this process have significantly facilitated this task. The process of applying any of the techniques or methodologies to monitor, detect and diagnose faults in electric motors has stages that are common to all, and the differences are due to the particularities of each technique. The generic steps for a process of detecting and diagnosing failures in electric induction motors include sensing, acquiring, filtering, processing and monitoring the signal for detection and diagnosis (see Figure 6) [64,65]. The equipment used in each of these phases is shown in Table 11.

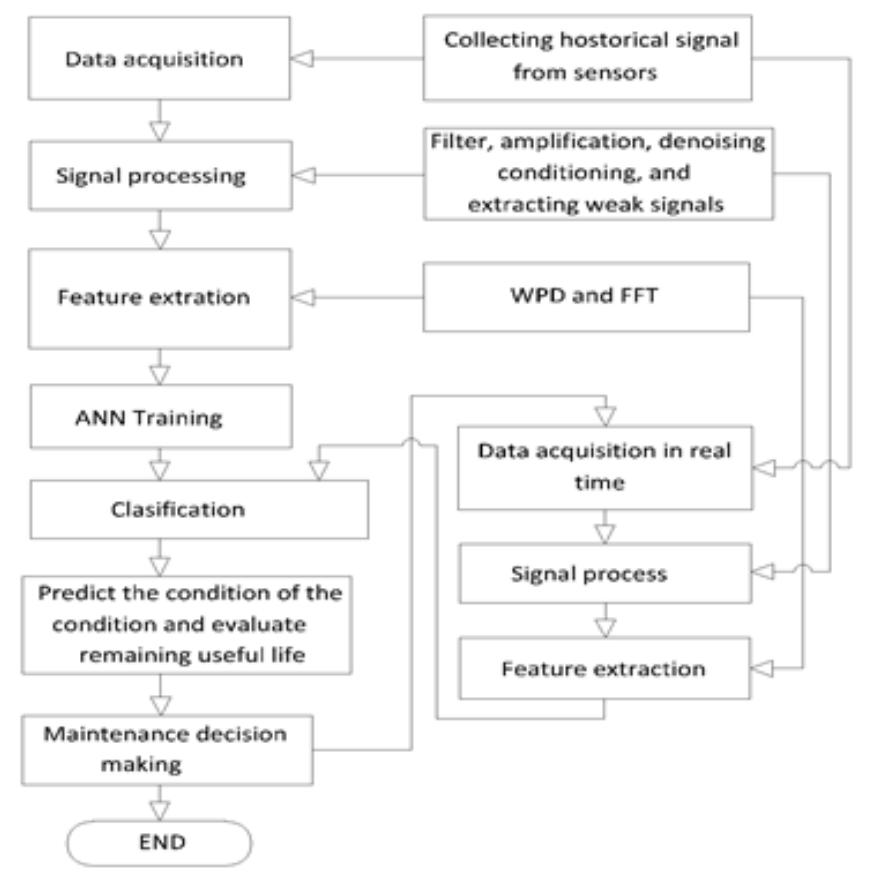

Figure 6. Stages of the process for the monitoring, detection and diagnosis of early failures. Fault diagnosis through WPD, FFT and ANN, as shown in [64]. Reproduced with permission from Springer, 2017.

Table 11. Software and hardware used according to the stage of the diagnostic process.

\begin{tabular}{clc}
\hline \multicolumn{1}{c}{ Stage } & \multicolumn{1}{c}{ Equipment } & References \\
\hline & Fluke Hall Effect probe & {$[41,42]$} \\
& Micro electromechanical systems (MEMS) & {$[39,66]$} \\
Current sensor & model CSA-1V & {$[57]$} \\
& Wireless XBEE & {$[29]$} \\
& 3035B DYTRAN accelerometers & {$[67]$} \\
\hline & Current Clamp & {$[25]$} \\
Vibration sensor & MEMS model LIS3L02AS4 & {$[26]$} \\
& DeltaTron accelerometer type 4517 & {$[57]$} \\
& Wireless XBEE & {$[64]$} \\
\hline Sound sensor & Kistler: Type 8702B100 & {$[68]$} \\
\hline & OLYMPUS WS 200S & {$[37,41,52,64,69]$} \\
& PCI-6250 M DAQ NI & {$[26,41]$} \\
& NI-6251 & {$[70]$} \\
& NI-9234 & {$[56]$} \\
& AT-MIO-16D data A/D card & {$[51]$} \\
& DSP 56F8357 & {$[71]$} \\
& 13-channel IO Tech & {$[68]$} \\
& ARCOM acquisition board & {$[25]$} \\
& MEMS model ADS7841 & {$[67]$} \\
\hline & FPGA-based System & {$[64]$}
\end{tabular}




\begin{tabular}{llc} 
acquiring signals & NI cDAQ-9172 & {$[70]$} \\
\hline & MATLAB and LabVIEW & {$[41,42,64,69]$} \\
& MATLAB & {$[32,37,41,51,53,59,67,69,70,72-74]$} \\
Signal analysis & LabVIEW & {$[44]$} \\
& NI Sound and Vibration Assistant software & {$[70]$} \\
& NI DAQ Ware 4.5 & {$[56]$} \\
\hline
\end{tabular}

One of the most used technologies for this purpose is that developed by the company National Instruments (NI), which offers tools for each of the stages mentioned. Of the papers considered, $50 \%$ use 6250 or 6251 cards for data acquisition, and 100\% use LabVIEW or MATLAB for the monitoring and analysis of the signal at a basic or advanced level, either in academic or commercial environments. LabVIEW can handle complex problems with a basic level of programming, while MATLAB is used for the mathematical tools that it offers for the analysis and treatment of the signals. NI technology is usually implemented in conjunction with MATLAB. The signal is acquired and conditioned by a card, such as NI-6251, monitored by LabVIEW and treated by MATLAB.

Ranga and Chandel [75] state that "LabVIEW" is the best alternative for condition monitoring, diagnosis and parameter identification of induction machines. In addition to signal measurements are very easy, LabVIEW allows realizes virtual instruments. According the authors, applications developed with LabVIEW include the following:

- On-line health monitoring of induction motors by using LabVIEW to diagnose the mechanical faults.

- Analysis of induction motor performance.

- Internet technology-based development of remote diagnosis to check the machine status through the Internet and mobile terminals.

- $\quad \mathrm{CM}$ of AC motors through intelligent fault diagnosis based on programmable logic controllers.

- Analysis of three-phase induction motor using the current Park's vector.

The constant evolution in the development of new methodologies for monitoring and detecting failures in induction motors has also reached the tools and instrumentation to capture, treat and analyze the signals. According to Son et al. [66], traditional vibration sensors, sound, temperature, filters, current and voltage transformers are being replaced by Micro Electromechanical Systems (MEMS). MEMS technology refers to microscopic electromechanical devices built on a chip, which can be combined with artificial intelligence techniques. Although this technology is not yet completely tested and requires many improvements before its application in the monitoring and detection of faults in induction motors, the authors demonstrate in their experimental study the sufficiency of MEMS to replace conventional sensors in the detection of shaft twists, mass imbalance, defective bearings and broken bars.

Alarcón [39], uses the CSA-1V sensor ( $5 \mathrm{~mm}$ long by $4 \mathrm{~mm}$ wide, Figure 7), with CMOS technology using the Hall effect, to measure the current of bars broken by fatigue. According to the author, this type of sensor does not introduce new resistances that alter the measurement and can be used in reduced spaces that do not allow the utilization of another type of sensor. Additionally, these sensors tolerate the electromagnetic effect, tolerate up to 125 degrees Celsius and have an insulation capacity of up to $600 \mathrm{~V}$.

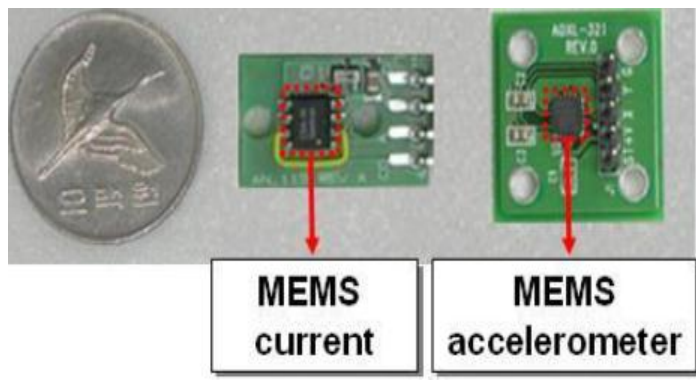

Figure 7. MEMS sensors for current and accelerometers, as shown in [66]. Reproduced with permission from Elsevier, 2017. 
Wireless sensors represent a new technological breakthrough. Aydın et al. [57] proposed a network of these types of sensors to monitor and diagnose the failures of several motors simultaneously through the signals of current and voltage. The author uses the current signal obtained along with a Fuzzy Logic approach to diagnose stator faults. For bearing problems, the signal from the vibration sensors is normalized to construct the phase space and analyze their changes with machine learning techniques based on Gaussian Mixture Models and Bayesian classification.

\section{Failures According to the Part of the Machine and Diagnostic Methods}

In this section, we intend to summarize the identification of the faults through the application of what has been described thus far in the present work. For this, the section is divided according to one of the methods of grouping the different types of faults of the induction motors, that is, as faults occur in the stator, rotor or bearings. Each of these parts may have several types of faults and these can be detected by the use of various types of signals and methods, as below.

\subsection{Rotor Failures}

\subsubsection{Broken Bars}

The presence of broken bars in the rotor can be detected by several methods, including analysis of the equivalent circuit of the motor, VA and MCSA. As seen thus far, several faults may occur in the rotor. Concerning the bars, damage in this part of the machine will be reflected in the current signal in the form of harmonics, being the most important those located at $\pm 2 s f$ of the fundamental wave, where $s$ means the slip, and $f$ means the frequency of the network. The severity of bars damage depends on the amplitude of the harmonic. Thus, the greater the difference with respect to the amplitude of the fundamental wave, the greater the damage, Thomson and Fenger [33], Soto and De la Torre [45]; see Figure 8 and Table 12. Benbouzid [46] stated that current analysis does not allow for detection of the distribution of bars in the rotor when these are broken and located in various parts of the engine. However, when the amplitude of the harmonics is $50 \mathrm{~dB}$, smaller than the fundamental wave, it could be considered that the motor is in good condition.

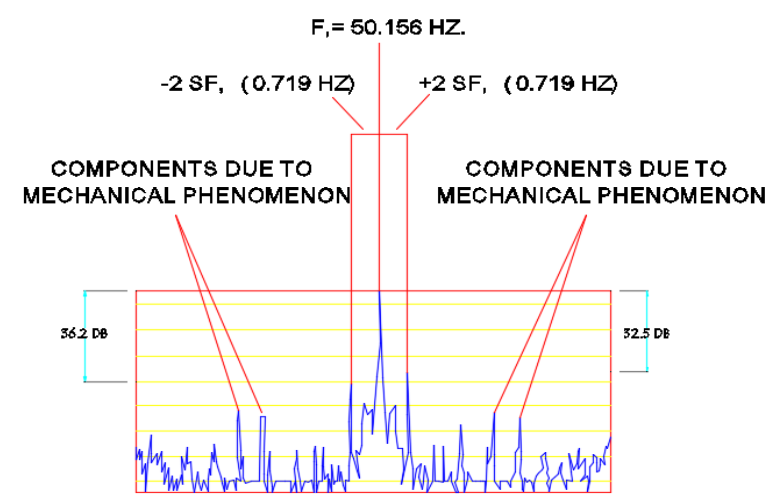

Figure 8. FFT spectrum of the current signal of a motor with a broken bar, as shown in [33]. Reproduced with permission from IEEE, 2017.

Table 12. Difference of amplitude between the fundamental harmonic and sidebands.

\begin{tabular}{cc}
\hline Motor Condition & Amplitude Difference (dB) \\
\hline Healthy & $54-60$ \\
Acceptable & $48-54$ \\
Half section broken bar & $42-48$ \\
One broken bar & $36-42$ \\
Many broken bar & $30-36$ \\
Severe problems & $<30$ \\
\hline
\end{tabular}


According to Benbouzid et al. [49], the components of the current spectrum of a motor, produced by irregularities of the magnetic field due to broken bars, are given by (12). Where due to the winding configuration, $k / p=1,2,3, \ldots$

$$
f_{b r b}=f\left\{k \frac{(1-s)}{p}+/-s\right\},
$$

Since rotor failures are not so common and it may take some time for the machine to collapse, the most interesting investigations are focused on quantifying the magnitude of the failure in its early state. In these case MCSA would be useful if mathematical models considered saturation, bar currents, and magnetic asymmetries. For this reason the mentioned variables are found in several models presented by the authors in their study, which includes Table 13, showing the indices related to several failures and their associated wave components [23].

where:

$I=$ Magnitude of the fundamental component of the current

$I_{1}=$ Amplitude of the left lateral component (stator current) referred to its original component

$N_{r}=$ Number of rotor bars

$n_{r}=$ Number of continuous broken bars

$P=$ Number of poles

$\gamma=\left(2 \pi /\left(N_{r} / P\right)\right) \mathrm{n}_{r}$

$I_{d B}=\left[20 \log _{10}\left(I_{1} / I\right)+20 \log _{10}\left(I_{1} / I\right)\right] / 2$

Table 13. Quantitative methods for detecting rotor failures.

\begin{tabular}{cc}
\hline Signal Components & $\boldsymbol{n}_{\boldsymbol{r}}$ \\
\hline$(1-2 s) f$ & $\frac{I_{1}}{I}=\frac{\sin \gamma}{2 P(2 \pi-\gamma)} \gamma=\frac{2 \pi}{N_{r} / P} n_{r}$ \\
$(1+/-2 s)$ & $\frac{I_{1}}{I}=\frac{I_{1}+I_{r}}{I} \cong \frac{n_{r}}{N_{r}}$ \\
$(1+/-2 s) f$ & $n_{r}=\frac{2 N_{r}}{10^{-\frac{I_{d B}}{20}}+P}$ \\
\hline
\end{tabular}

When the vibration signal is used, according to [45], a bar breakage is manifested as harmonics in the vibration spectrum, whose width is given by (13).

$$
d=2 p \frac{N_{s}-N}{60}
$$

where:

$P=$ Number of pole pairs of the motor

Ns $=$ Sync speed $(\mathrm{rpm})$

$N=$ Asynchronous speed (rpm)

Perhaps as a qualitative step in the analysis of the behavior of induction motors through its equivalent circuit proposed by Steinmetz in 1897 and thanks to the advance of other branches of the sciences such as electronics, computation, and signal analysis, it has been possible the development and use of new mathematical models derived from the equivalent circuit of the motor to detect asymmetries in its current, torque, speed, etc. Filippetti et al. [12] suggested two techniques based on the equivalent circuit (Figure 9) to identify broken bars by relating them to the equivalent rotor resistance and the relation between the currents induced in the stator by the components of the rotor current. The first component of the field in the air gap rotates in the same direction as the rotor and will induce a current I in the stator, while the second component rotating in the opposite direction will induce a current $\mathrm{I}_{2}$. Considering that both $\mathrm{I}_{2}$ and $\mathrm{I}$ depend on the slip and the number of broken bars, the ratio $\mathrm{I}_{2} / \mathrm{I}$ is indicative of a failure in the rotor, as well as increased rotor resistance. According to the authors, since several assumptions are made and the temperature effect on the resistance increase is not considered, these techniques would be valid for motors with a broken bar. 


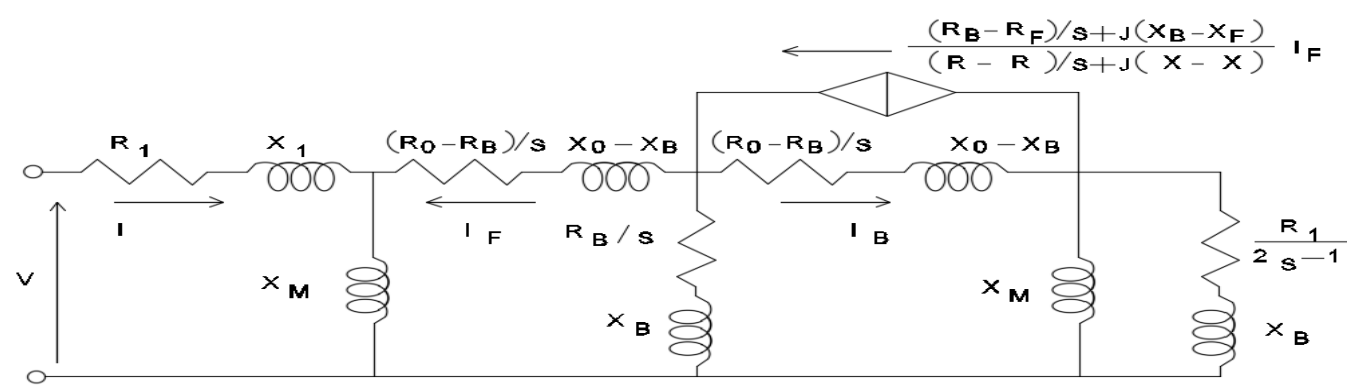

Figure 9. Equivalent motor circuit in a stable state with rotor asymmetries, as shown in [12]. Reproduced with permission from IEEE, 2017.

\subsubsection{Eccentricity}

The eccentricity can be static, dynamic or mixed and can be caused by a deviated or twisted shaft and defective or poorly positioned bearings. According to the studies, the phenomena associated with eccentricity are reflected in the speed and torque of the machine, which is observed in the frequency spectrum of the current as side bands given by (14), Bellini et al. [23]:

$$
f_{e c}=f_{1}\left\{\left(R+/-n_{d}\right) \frac{(1-s)}{p}+/-n_{w s}\right\},
$$

where:

$f_{e c}=$ Components associated with eccentricity

$f_{1}=$ Frequency of the network

$R=$ Number of rotor slots

$s=$ Sliding

$p=$ Pairs of poles

$n_{d}= \pm 1$

$n_{w s}=1,3,5,7 \ldots$

Benbouzid [46], proposed a method for determining the components of the velocity and torque spectrum $\left(f_{\text {slot }+e c c}\right)$ and another that defines the lateral bands $\left(f_{\text {ecc }}\right)$ of the motor power supply.

$$
\begin{gathered}
f_{\text {slot }+e c c}=f_{s}\left\{\left(k R+/-n_{d}\right) \frac{(1-s)}{p}+/-n_{w}\right\}, \\
f_{e c c}=f_{s}\left\{1+/-m\left(\frac{(1-s)}{p}\right)\right\},
\end{gathered}
$$

When the eccentricity is dynamic, the air gap change alters its flux density and the machine inductance, producing components in the signal of the stator current, which are given by (17) [49].

$$
f_{\text {sso }}=f\left\{k \frac{(1-s)}{p}+/-1\right\},
$$

\subsubsection{Rotoric Asymmetry}

According to [49], when rotor asymmetry occurs, it will create a disturbance in the air-gap flux density. The disturbance rotates at the same speed as the rotor and will be reflected in the current signal of the stator in the form of bands, caused by:

$$
f_{r a}=f\left\{k \frac{(1-s)}{p}+/-s\right\}
$$

\subsection{Bearings}

Vibrations, continuous internal stresses, eccentricity, rotor and shaft currents, contamination, corrosion, lack of lubrication, high temperature, poor installation, natural wear due to the time of use and damage of engine covers are causes for failures of the spheres and mainly the inner and 
outer tracks of the bearings. These failures cause the natural vibrations and sounds of any machine to increase substantially, in addition there will be oscillations of speed and torque with characteristic frequency spectra. Bearing failures can be detected using stator current, temperature, vibration and acoustic analyses. Of these alternatives, the most commonly used are vibrational analysis and MCSA; although both are of a different nature, some studies relate the two signals [23].

\subsubsection{Failure Detection through Stator Currents}

The lateral bands associated with the eccentricity of the rotor caused by defects in bearings are given by (19) [49].

$$
f_{b n g}=f+/-n_{b} \frac{n}{2} f_{r}\left[1+/-\frac{B D}{P D} \cos \beta\right],
$$

where:

$f=$ Frequency of the network

$n_{b}=$ Number of spheres

$f_{r}=$ Mechanical speed of the rotor $(\mathrm{Hz})$

$B D=$ Diameter of the spheres

$P D=$ Bearing pitch diameter

$\beta=$ Contact angle between the spheres and the tracks

$n=1,2,3, \ldots$

If the number of spheres is between six and twelve, the characteristic frequencies of failures can be approximated in most bearings by (20) and (21) [46].

$$
\begin{aligned}
& f_{0}=0.4 n f_{r}, \\
& f_{i}=0.6 n f_{r},
\end{aligned}
$$

For the bearings, according to [23], the frequencies of the components associated with the failure are given by:

$$
\begin{gathered}
F_{C}=\frac{1}{2} F_{R}\left(1-\frac{D_{b} \cos \beta}{D_{c}}\right), \\
F_{O}=\frac{N_{B}}{2} F_{R}\left(1-\frac{D_{b} \cos \beta}{D_{c}}\right), \\
F_{I}=\frac{N_{B}}{2} F_{R}\left(1+\frac{D_{b} \cos \beta}{D_{c}}\right), \\
F_{B}=\frac{D_{C}}{D_{b}} F_{R}\left[1-\left(\frac{D_{b} \cos \beta}{D_{c}}\right)^{2}\right],
\end{gathered}
$$

where:

$F_{c}=$ Failure frequency of the cage

$F_{o}=$ Failure frequency of the internal track

$F_{I}=$ Failure frequency of the external track

$F_{B}=$ Failure frequency of the spheres

$D_{b}=$ Diameter of the spheres

$D_{c}=$ Pitch diameter

\subsubsection{Detection of Failures through Vibrational Analysis}

For stationary signals, such as current or voltage during normal operation of the electric motor, MCSA is the best option for failure detection; however, for non-stationary signals, such as when starting the electric motor, it is preferable to use the analysis of noise and vibrations that are generated in all types of electric machines and can be of magnetic, mechanical or aerodynamic origin. 
There are four essential characteristics of the vibration signal that are needed to determine the asymmetries in the motor (through FFT); these are the amplitude (level of problem severity), frequency, phase, and modulation (the amplitude response of a frequency before another signal with a lower frequency). In the time domain, the analysis can be performed with the help of static measures, such as Root Mean Square (RMS), crest factor, and kurtosis [37]. When the bearings feature failures, they will be reflected in the frequency vibrations given by:

$$
\begin{aligned}
& f_{B P F O}=\frac{n}{2} \frac{N}{60}\left(1-\frac{d}{D} \cos \beta\right), \\
& f_{B P F I}=\frac{n}{2} \frac{N}{60}\left(1+\frac{d}{D} \cos \beta\right),
\end{aligned}
$$

where:

$f_{B P F O}=$ Ball pass frequency outer ring

$f_{B P F I}=$ Ball pass frequency inner ring

$\mathrm{n}=$ Number of balls

$N=$ Rotational speed (rpm)

$d=$ Ball diameter

$D=$ Bearing pitch diameter

$\beta=$ Ball contact angle with the race.

\subsection{Detection of Stator Failures}

Failures that occur in the stator, such as short circuits and unbalanced voltage, can be analyzed by the MCSA, the same signal used to determine several failures in other parts of the motor, such as the rotor and bearings.

\subsubsection{Detection of Stator Shortcuts through MCSA}

It is also possible to detect failures due to short circuits in the motor stator through MCSA. According to [33], the components of this type of failure in the stator current of low-voltage motors, induced by the rotational flux wave, are given by (28). An example of the application can be seen in Figure 10.

$$
f_{s t}=f_{1}\left\{\frac{n}{p}(1-s)+/-k\right\}
$$

where:

$f_{s t}=$ Components associated with the short circuit

$f_{1}=$ Frequency of the network

$s=$ Sliding

$p=$ Pairs of poles

$n=1,2,3,4, \ldots$

$k=1,3,5,7, \ldots$
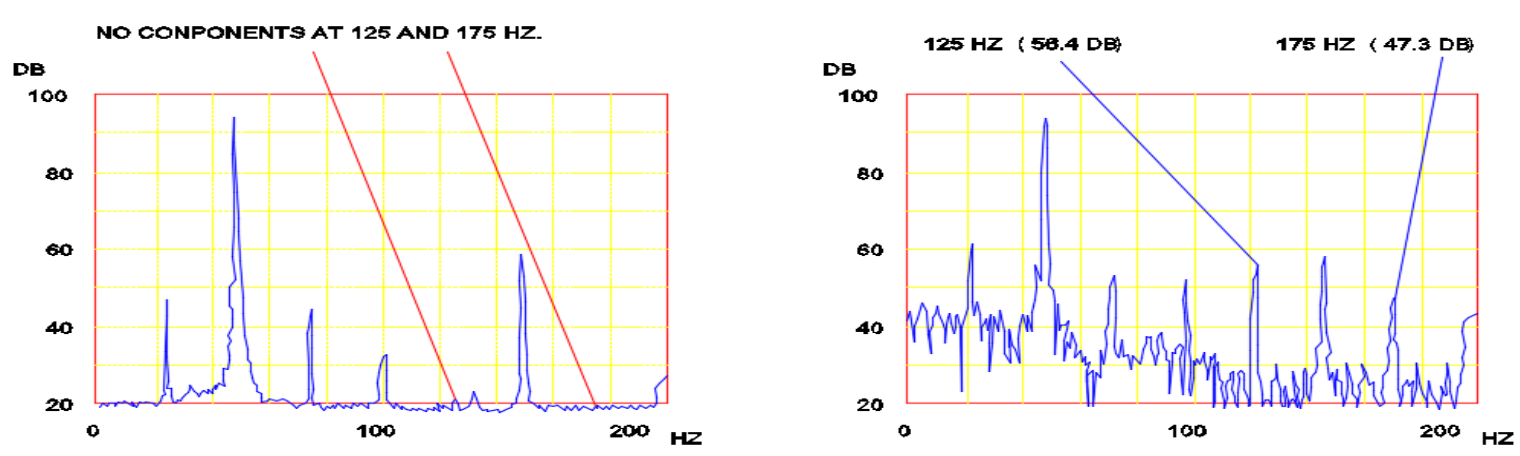

Figure 10. Spectrum FFT of the current signal of a motor with $20 \%$ burnt turns, as shown in [33]. Reproduced with permission from IEEE, 2017. 


\subsubsection{Stator Asymmetry}

Among the most widespread and simple methods for the early detection of stator asymmetries, the tracking of the negative sequence of motor currents occupies a prominent place. Through current (29) and voltage signals, the negative sequence impedance values are obtained, and the magnitude of the difference of these with respect to the average values of the machine indicates the severity of the failure. An effective procedure through the negative current sequence should distinguish between failures due to voltage unbalance, saturation, winding asymmetries, eccentricity and short circuits; however, a short circuit between turns is a failure that is difficult to detect, and generally, the machine will continue to work until it is out of service, Bellini et al. [23].

$$
\left[\begin{array}{l}
\bar{I}_{P} \\
\bar{I}_{n} \\
\bar{I}_{0}
\end{array}\right]=\frac{1}{3}\left[\begin{array}{ccc}
1 & \alpha & \alpha^{2} \\
1 & \alpha^{2} & \alpha \\
1 & 1 & 1
\end{array}\right]\left[\begin{array}{l}
\bar{I}_{u} \\
\bar{I}_{v} \\
\bar{I}_{w}
\end{array}\right]
$$

where:

$\bar{I}_{P}, \bar{I}_{n}, \bar{I}_{0}=$ Positive, negative and zero sequence currents, respectively

$\bar{I}_{u}, \bar{I}_{v}, \bar{I}_{w}=$ Line currents

$\alpha=e^{j \frac{2 \pi}{3}}$

Another important alternative for diagnosing stator asymmetries, especially in a transient state, is the modeling of the machine under fault conditions through equivalent circuits that can integrate the electrical and magnetic behavior. Bellini [23], describes several models, but according to the author, despite their scientific value, these still need to be investigated in depth to improve their accuracy and reliability and to make them applicable at an industrial level. One of the problems to be solved is the time lag between the identification of the failure and the collapse.

When MCSA is used for the determination of stator asymmetries in a fault-free motor, the most vital components are, according to [49], the first $(50 \mathrm{~Hz})$ and the fifth $(250 \mathrm{~Hz})$ harmonics, while in case of a voltage imbalance in the stator and regardless of the load, the affected components are the first and third harmonics $(150 \mathrm{~Hz})$; see Figure 11.
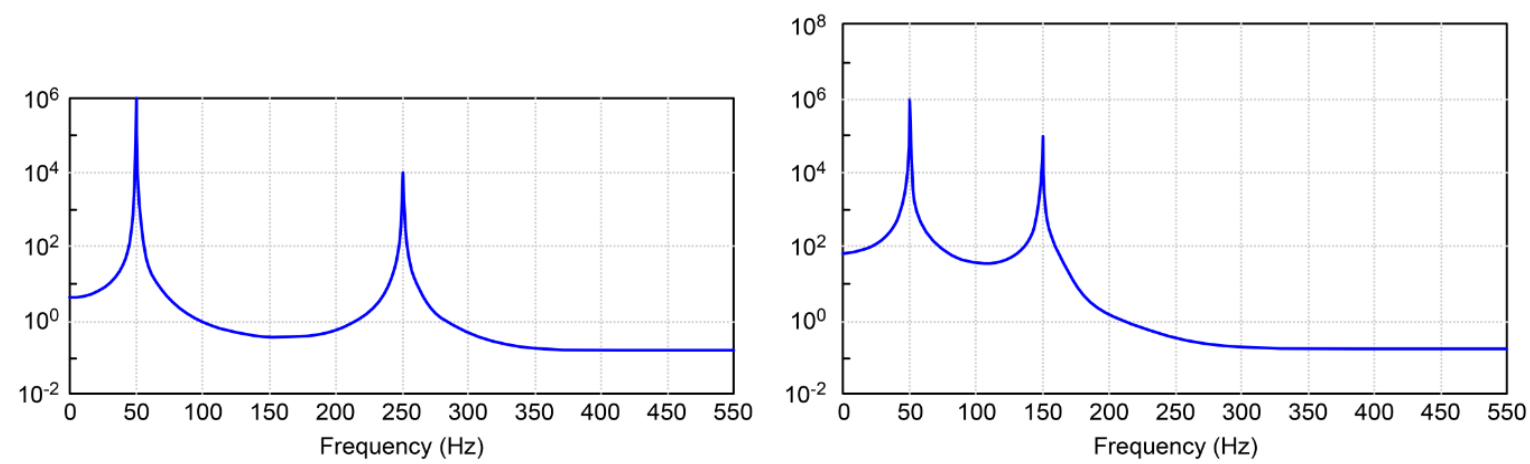

Figure 11. Frequency spectrum determined by music for a motor in good condition and another with voltage imbalance problems, as shown in [49]. Reproduced with permission from IEEE, 2017.

According to Drozdowski and Duda [36], the magnetic motor saturation will be reflected in the zero sequence voltage $\left(\mathrm{V}_{\mathrm{N}}\right)$ signal, as well as the machine asymmetries, where the $\mathrm{V}_{\mathrm{N}}$ spectrum in the stator can be used to detect rotor faults, which would be given by (32) and (33).

$$
\begin{gathered}
f_{s 1}=f_{s}\left|(1-\mu)-\frac{I Z_{r}}{p}(1-s)\right|, \\
f_{s 2}=f_{s}\left|(1-\mu)+\left(-\frac{I Z_{r}}{p}+2+6 k\right)(1-s)\right|, \\
f_{s 3}=f_{s 1}-\left.\left(n_{1}+1\right) s f_{s}\right|_{n 1=1}=f_{s 1}-2 s f_{s}, \\
f_{s 4}=f_{s 1}-\left.\left(n_{1}+1\right) s f_{s}\right|_{n 1=1}=f_{s 2}-2 s f_{s},
\end{gathered}
$$




\subsection{Combined Failures}

Most studies focus on the diagnosis of a determined type of failure or several of them but isolate each one. It is less frequent to find investigations focused on determining the presence of combined faults through signal analysis, García-Perez [25]. The author indicates that a safe and reliable alternative to determine single or multiple combined failures is through a FIR filter bank combined with high-resolution spectral-analysis (MUSIC). Applying this methodology, the bandwidths associated with different failures were identified and are shown in Table 14. Figure 12 shows the frequency spectra for a motor with more than one fault at the same time.
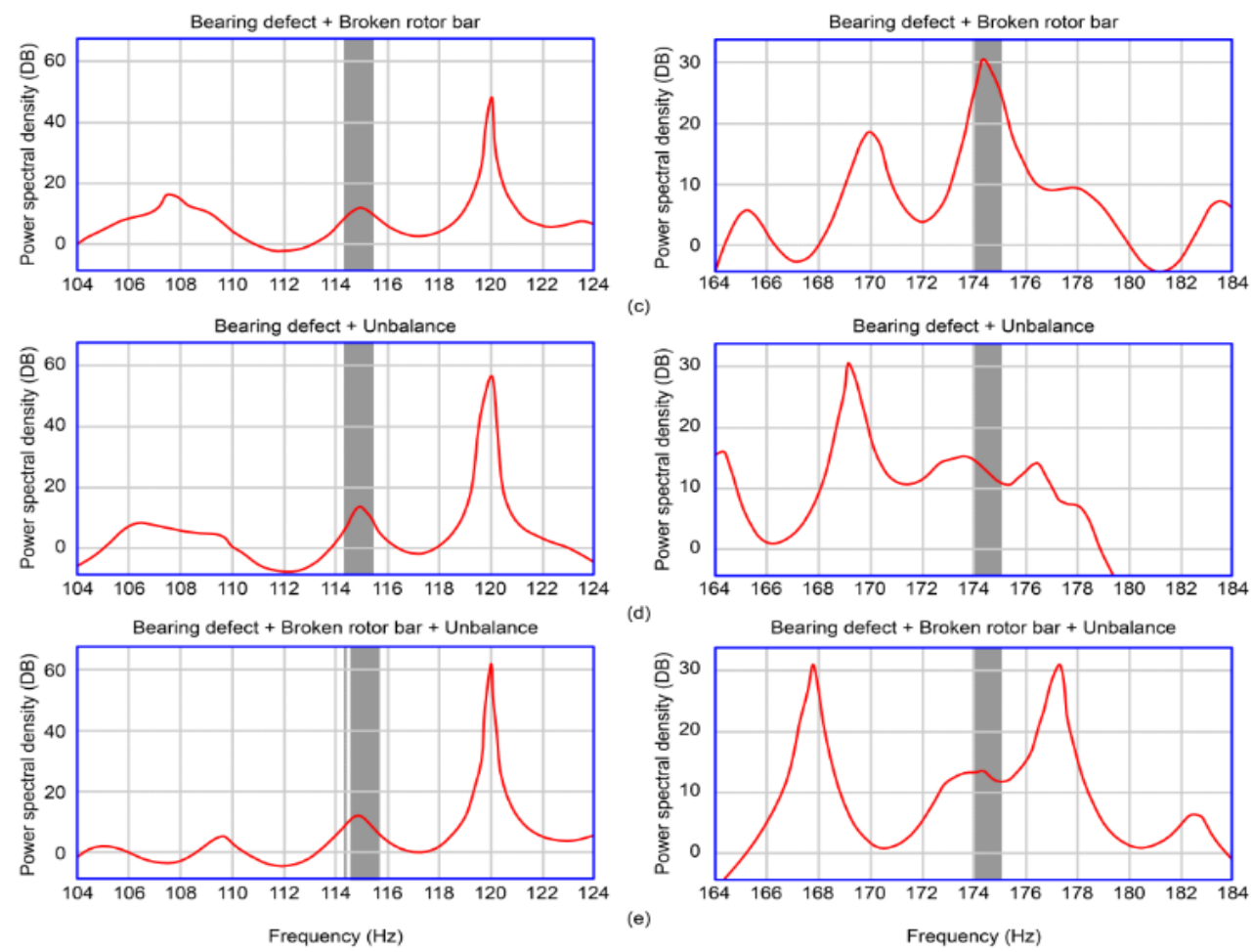

Figure 12. Detected components related to different combinations of failures through MUSIC, as to the signal of current and vibration, as shown in [25]. Reproduced with permission from IEEE, 2017.

Table 14. Bandwidth associated with failures.

\begin{tabular}{cc}
\hline Failure & Bandwidth (Hz) \\
\hline Broken bars & $45-75$ \\
Defective Bearings (current signal) & $104-124$ \\
Defective Bearings (vibration signal) & $164-184$ \\
Phase Unbalance & $45-65$ \\
\hline
\end{tabular}

\section{Predictive Maintenance Based on Artificial Intelligence Techniques}

Despite the advances in the methodologies developed for the diagnosis of failures in their initial phase, the techniques to capture, treat, monitor and diagnose based on the analysis of the signal have not been sufficient when working independently or isolated. It was necessary to develop expert systems that include the use of probability functions, incomplete data, and nonlinear systems. Thus, in this context, AI, which is a set of techniques that try to emulate the biological behavior of living entities, such as man (see Table 15), to autonomously be able to learn, adapt and make the best decisions, would become the new alternative to solve many complex problems in both science and engineering, such as that of autonomously, accurately and reliably interpreting the information contained in the signals of the induction motors to provide an early warning of failures, $[63,76,77]$. 
Table 15. AI techniques.

\begin{tabular}{cl}
\hline Techniques & Emulated Phenomenon \\
\hline ANN & Learning and classifying patterns like the human brain \\
\hline Fuzzy Logic & $\begin{array}{l}\text { How the brain handles inaccurate information and makes inferences } \\
\text { Stores the experience in a linguistic form }\end{array}$ \\
\hline $\begin{array}{c}\text { Neuro-Fuzzy System } \\
\text { (Hybrid Systems) }\end{array}$ & $\begin{array}{l}\text { Learning and classifying patterns like the human brain, making } \\
\text { inferences based on inaccurate information and storing experience in } \\
\text { a linguistic form }\end{array}$ \\
\hline $\begin{array}{c}\text { Genetic Algorithm } \\
\text { Support Vector } \\
\text { Machine (SVM) }\end{array}$ & $\begin{array}{l}\text { Selection of the best adapted } \\
\text { Chromosomes, Genes }\end{array}$ \\
\hline $\begin{array}{c}\text { K-nearest neighbors } \\
\text { (KNN) }\end{array}$ & Estimates the probability that an element belongs to a given set \\
\hline Data Mining & $\begin{array}{l}\text { Techniques to process large databases to find patterns of trends that } \\
\text { explain their behavior }\end{array}$ \\
\hline $\begin{array}{c}\text { Case-Based } \\
\text { Reasoning (CBR) }\end{array}$ & Troubleshooting based on similar previous cases \\
\hline Expert Systems & $\begin{array}{l}\text { Computer system that performs inferences based on stored data and } \\
\text { received information }\end{array}$ \\
\hline
\end{tabular}

In addition to the classical analysis techniques, which are based on studying the frequency spectrum of signals, AI techniques such as fuzzy logic, ANN, and approximate sets have recently been implemented. While the techniques analyzed thus far are based on deterministic models, artificial intelligence techniques use probability functions to handle uncertainty, imprecision, nonlinear systems and incomplete data [31,78]. According to the authors, predictive maintenance is currently based on online monitoring of the conditions, detection, and diagnosis of failures and measurement of the effectiveness of the maintenance actions applied using AI techniques. AI techniques cannot be analyzed separately from MCSA-based methods; they are a complement, extension or step forward in the effort to refine the procedures applied to give a more accurate, reliable and efficient diagnosis of the emerging failures in induction engines. In fact, all the asymmetries detected with the aid of non-invasive techniques that were analyzed in section two are the same failures that are to be diagnosed through $\mathrm{AI}$, whose mathematical models are fed by the signals treated through MCSA techniques.

According to Ding [58], AI techniques constitute the core of SC and, along with other modern technologies, have an unprecedented influence on intelligent systems that imitate a human being in learning, reasoning and intelligence. These have been applied to solve several engineering problems, including on-line monitoring and diagnosis of emerging failures in electric motors.

Additional examples of SC techniques applied to the predictive maintenance of induction machines include the Terology Integrated Modular System (SMIT) and the Intelligent System for Predictive Maintenance (SIMAP). SIMAP employs neural networks, fuzzy expert systems, and fuzzy genetic algorithms, while SMIT uses Support Vector Regression (SVR), Autoregressive Moving Average (ARMA) and Autoregressive Integrated Moving Average (ARIMA) [31]. According to Bellini et al. [23], so that AI-based diagnostic systems have a minimum configuration, provide a proper diagnosis and apply to the industrial field, the best alternative would be to combine several AI techniques. This would allow us to meet the minimum requirements, which are as follows:

1. To be as simple as possible, i.e., having a minimum number of indicators, neurons, and rules.

2. To require minimum prior knowledge. 
3. To have the most important steps of a system that uses SC techniques to perform a diagnosis as shown in Figure 13.

\begin{tabular}{|c|c|c|}
\hline Adquisition and & $\begin{array}{l}\text { Use of an ANN or a combination } \\
\text { of fuzzy logic with an adaptive }\end{array}$ & $\begin{array}{l}\text { Use of Supervised Neural Network } \\
\text { (SNN) such as Multilayer }\end{array}$ \\
\hline signal processing & $\begin{array}{l}\text { NN to classify the data into } \\
\text { vectors, corresponding to the } \\
\text { different types of failures }\end{array}$ & $\begin{array}{l}\text { Perceptron (MLP) to relate input } \\
\text { vectors with diagnostic rates }\end{array}$ \\
\hline
\end{tabular}

Figure 13. Stages of the monitoring, detection and diagnosis process using Soft Computing (SC) techniques, as shown in [23].

At present, there are many studies on the application of AI and SC for the monitoring and diagnosis of almost all failures in electric induction motors. Despite this being an extensive subject, a summary of the works considered in the present research is provided in Table 16, grouped according to the type of failure and the technique applied.

The techniques based on artificial intelligence are one of the last evolutionary stages of science and technology applied to the monitoring, detection, and diagnosis of failures in the electric induction motors. Due to mechanical, electrical, electronic and software equipment, the signals are captured and conditioned to feed complex mathematical models capable of detecting failures, interpreting and performing the best diagnosis. As Benjamin Lamme said in the 1890s, referring to the years between 1880 and 1890, "We are in the decade of the induction motor," [9]. Today, in reference to the monitoring, detection and diagnosis of the state of electric motors, we could say that we are in the days of AI.

Table 16. AI techniques according to the type of fault analyzed.

\begin{tabular}{|c|c|c|c|c|c|c|c|c|c|}
\hline \multirow[b]{2}{*}{ Signal } & \multirow{2}{*}{\multicolumn{2}{|c|}{ Applied Techniques }} & \multicolumn{7}{|c|}{ Faults } \\
\hline & & & $\begin{array}{c}\text { Broken } \\
\text { Bars }\end{array}$ & Bearings & $\begin{array}{l}\text { Eccentri } \\
\text { city }\end{array}$ & Unbalance & $\begin{array}{c}\text { Windings } \\
\text { Short }\end{array}$ & $\begin{array}{l}\text { Voltage } \\
\text { Unbalance }\end{array}$ & $\begin{array}{c}\text { Degradation } \\
\text { of } \\
\text { Components } \\
\text { Prediction } \\
\end{array}$ \\
\hline \multirow{7}{*}{ Current } & \multirow{4}{*}{ ANN } & $\begin{array}{l}\text { Feed Forward } \\
\text { Propagation }\end{array}$ & {$[32,79]$} & {$[32]$} & [32] & [32] & & & \\
\hline & & $\begin{array}{l}\text { Recurrent } \\
\text { Dynamic }\end{array}$ & & [80] & [80] & & [80] & & \\
\hline & & $\begin{array}{l}\text { Feed Forward } \\
\text { Propagation } \\
\text { Adaptive } \\
\text { linear network }\end{array}$ & [67] & {$[67]$} & & [67] & & & \\
\hline & & $\begin{array}{l}\text { Negative } \\
\text { sequence } \\
\text { current }\end{array}$ & & & & & [51] & & \\
\hline & Fuzzy logic & & & & & & {$[57,81]$} & {$[57,81]$} & \\
\hline & $\begin{array}{l}\text { Hybrid } \\
\text { systems }\end{array}$ & $\begin{array}{l}\text { Feed-forward } \\
\text { MLP ANFIS }\end{array}$ & & & & & [73] & & \\
\hline & Fuzzy sets & & [82] & {$[82]$} & [82] & & [82] & & \\
\hline \multirow{8}{*}{$\begin{array}{l}\text { Vibrati } \\
\text { on }\end{array}$} & ANN & $\begin{array}{l}\text { Back } \\
\text { propagation }\end{array}$ & & & & [80] & & & {$[64]$} \\
\hline & & MLP & {$[71]$} & & & & & & \\
\hline & \multirow{4}{*}{ SVM } & & & {$[48]$} & {$[48]$} & {$[48]$} & & & \\
\hline & & $\begin{array}{l}\text { Hilbert-Huan } \\
\text { gttransform } \\
\text { (HHT), SVR }\end{array}$ & & [29] & & & & & \\
\hline & & $\begin{array}{l}\text { Sparse } \\
\text { representation }\end{array}$ & & {$[65]$} & & & & & \\
\hline & & $\begin{array}{l}\text { wavelet } \\
\text { packet } \\
\text { decompositio } \\
\mathrm{n}\end{array}$ & & [77] & & & & & \\
\hline & KNN & & & & & [83] & & & \\
\hline & $\begin{array}{l}\text { Hybrid } \\
\text { Systems }\end{array}$ & $\begin{array}{l}\text { Left Right } \\
\text { type fuzzy } \\
\text { numbers } \\
\text { ANN Wavelet }\end{array}$ & & {$[84]$} & & & & & \\
\hline
\end{tabular}




\begin{tabular}{lll}
\hline decompositio & & \\
$\mathrm{n}$ & & \\
Fuzzy Logic & \\
\hline ANFIS & {$[85]$} & {$[85]$} \\
\hline
\end{tabular}

\section{Conclusions and Recommendations}

Until now, a significant number of techniques and methodologies has been developed to monitor, detect and diagnose the failures of electric induction motors. Many of these studies have high scientific utility for modeling the behavior of the motor in the diverse situations associated with the types of failures that may occur. However, a good number of them assume many idealizations, making them not immediately applicable, but their study should be deepened to a level where they may even be standardized, along with other existing techniques and methodologies. There are few studies on possible solutions to the faults being investigated, which could lead us to studies related to the materials used to build the engines, new designs and manufacturing processes.

We cannot discard further research to improve the traditional detection and diagnostic techniques in methods that could range from using the equivalent circuit of the motor to simulate and predict its behavior to specific methods for the wide variety of failures featured by this type of machine, such as short circuits between turns, or to determine the length of time that a motor can continuing working after detecting a fault. However, the latest wave in methodologies for the diagnosis of induction motor failures is SC based on AI techniques. Investigations should be deepened to achieve systems as close as possible to human systems, capable of diagnosing each of the failures individually and the combination of several of these when they occur simultaneously.

Despite the advances in techniques for early diagnosis of induction motor failures, the IEEE 1415-2006 standard states that "there are no test programs that can replace the need for a visual inspection." This paradigm should suppose a major challenge to break. Just as invasive and non-invasive tests that rely on the analysis of frequency spectra, many works on the application of $\mathrm{SC}$ to diagnose specific types of failure are reported. However, it is rare to find cases where AI is part of a more advanced system applied to our field, that is, able to learn, answer questions by voice command, find the means to locate and communicate with a person about any anomaly, schedule maintenance and even solve problems.

Acknowledgments: This work was developed thanks to the help of the University of Guayaquil, through the granting of a scholarship for the doctoral studies of the author. The author wishes to express his gratitude to the University of Valladolid and the University of Guayaquil for his help in carrying out this work.

Conflicts of Interest: The authors declare no conflict of interest.

\section{References}

1. Hunt, B. Pursuing Power and Light: Technology and Physics from James Watt to Albert Einstein, 1st ed.; Johns Hopkins University Press: Baltimore, MD, USA, 2010; pp. 14-134; ISBN 100801893593.

2. Hernández, M.; Prieto, J. Historia de la Ciencia Vol II, 1st ed.; Fundacion Canaria Orotawa de Historia de la Ciencia: Tenerife, Spain, 2007; pp. 54-69; ISBN 978-84-612-4246-7.

3. Shu-Hua, P. Origine de la Boussole. J. Hist. Sci. Soc. 1954, 45, 175-196.

4. May, W. The birth of the compass. J. Navig. 1949, 2, 259-263, doi:10.1017/S0373463300031969.

5. Daub, W.; Seese, W. Química, 8th ed.; Prentice Hall: Mexico City, Mexico, 1998; pp. 57-82; ISBN 970-26-0694-2.

6. Arya, S. Fundamentals of Magnetism and Electricity; Navyug Publishers \& Distributors: New Delhi, India, 2009; pp. 60-65.

7. Cheng, D. Fundamentos de Electromagnetismo Para Ingeniería, 1st ed.; Addison-Wesley Iberoamericana: Wilmington, Delaware, USA, 1997; pp. 196-197; ISBN 0-201-65375-3.

8. Hughes, A.; Drury, B.; MacLoud, D. Electric Motors and Drives: Fundamentals, Types and Applications, 3rd ed.; Elsevier: Oxford, UK, 2005; pp. 185-191; ISBN 978-0-7506-4718-2.

9. Kline, R. Science and engineering theory in the invention and development of the induction motor, 18801900. Technol. Cult. 1987, 28, 283-313. 
10. Pyrhonen, J.; Jokinen, T.; Hrabovcova, V. Design of Rotating Electrical Machines, 2nd ed.; John Wiley \& Sons: Chichester, UK, 2013; pp. 3-4; ISBN 978-0-470-69516-6.

11. Trzynadlowski, A. Detection of mechanical abnormalities in induction motors by electric measurements. Int. J. Rotat. Mach. 1999, 5, 41-52.

12. Filippetti, F.; Franceschini, G.; Tassoni C.; Vas, P. Broken bar detection in induction machines: Comparison between current spectrum approach and parameter estimation approach. In Proceedings of the Conference Record of the 1994 IEEE Industry Applications Society Annual Meeting, Denver, USA, 2-6 October 1994; pp. 95-102. doi: 10.1109/IAS.1994.345493

13. Serway, R.; Jewett, J. Física Para Ciencias e Ingeniería, 6th ed.; Cengage Learning: Ciudad de México, México, 2007; pp. 191-250; ISBN 970-686-425-3.

14. Ferreira, B.; Van der Merwe, W. The Principles of Electronic and Electromechanic Power Conversion: A Systems Approach; John Wiley \& Sons: Hoboken, NJ, USA, 2013; pp. 56-61; ISBN 978-1-118-65609-9.

15. Sundararajan, D. The Discrete Fourier Transform: Theory, Algorithms and Applications, 1st ed.; World Scientific Publishing Company: Singapore, 2001; pp. 1-11; ISBN 9789812810298.

16. Hansen, E. Fourier Transforms: Principles and Applications, 1st ed.; John Wiley \& Sons: Hoboken, NJ, USA, 2014; pp. 109-278; ISBN 978-1-118-47914-8.

17. Stranneby, D.; Walker, W. Digital Signal Processing and Applications, 2nd ed.; Elsevier Science: Burlington, MA, USA, 2014; pp. 131-139; ISBN 0750663448.

18. Boukra, T.; Lebaroud, A. Classification of induction machine faults, Systems Signals and Devices (SSD). In Proceedings of the 7th IEEE International Multi-Conference, Amman, Jordan, 27-30 June 2010; pp. 1-6.

19. Institute of Electrical and Electronics Engineers (IEEE). IEEE Guide for Induction Machinery Maintenance Testing and Failure Analysis. IEEE Standards. Available online: https://dialnet.unirioja.es/servlet/ tesis?codigo=38169 (accessed on 12 January 2016).

20. Peña, H.; Ramirez, C.; Ledezma, E. Maintenance Testing and Failure. Energía y Computación 1994, 8, 71-76.

21. O'Donnell, P. Report of large motor reliability survey of industrial and commercial installations, Part I. IEEE Trans. Ind. Appl. 1985, IA-21, 853-864, doi:10.1109/TIA.1985.349532.

22. Bonnett, A. Root cause AC motor failure analysis with a focus on shaft failures. IEEE Trans. Ind. Appl. 2000, 36, 1435-1448, doi:10.1109/PCIC.2010.5666831.

23. Bellini, A.; Filippetti, F.; Tassoni, C.; Capolino, G. Advances in diagnostic techniques for induction machines. IEEE Trans. Ind. Electron. 2008, 55, 4109-4126, doi:10.1109/TIE.2008.2007527.

24. Zhang, P.; Du, Y.; Habetler, T.; Lu, B. A survey of condition monitoring and protection methods for medium-voltage induction motors. IEEE Trans. Ind. Appl. 2011, 47, 34-46, doi:10.1109/TIA.2010.2090839.

25. Garcia-Perez, A.; Romero-Troncoso, R.; Cabal-Yepez, E.; Osornio-Rios, R. The application of high-resolution spectral analysis for identifying multiple combined faults in induction motors. IEEE Trans. Ind. Electron. 2011, 58, 2002-2010, doi:10.1109/TIE.2010.2051398.

26. Bianchini, F.; Monteiro, P.; Pederiva, R.; Diniz, V. An empirical demodulation for electrical fault detection in induction motors. IEEE Trans. Instrum. Meas. 2016, 65, 559-569, doi:10.1109/TIM.2015.2509398.

27. Costa, A. Investigación de Nuevas Técnicas de Mantenimiento de Parques Eólicos. Ph.D. Thesis, Department of Marine Power and Propulsion, Coruña University, Coruña, Spain, 2012.

28. Haji, M.; Toliyat, H. Pattern recognition-A technique for induction machines rotor broken bar detection. IEEE Trans. Energy Convers. 2001, 16, 312-317, doi:10.1109/IAS.2001.955745.

29. Soualhi, A.; Medjaher, K.; Zerhouni, N. Bearing health monitoring based on Hilbert-Huang transform, support vector machine, and regression. IEEE Trans. Instrum. Meas. 2015, 64, 52-62, doi:10.1109/TIM.2014.2330494.

30. Das, A.; Maiti, J.; Banerjee, R. Process monitoring and fault detection strategies: A review. Int. J. Q. Res. Manag. 2012, 29, 720-752, doi:10.1108/02656711211258508.

31. Alsyouf, I.; Alzghoul, A. Soft computing applications in wind power systems: A review and analysis. In Proceedings of the European Offshore Wind 2009 Conference Exhibition, Stockholm, Sweden, 14-16 September 2009.

32. Aroui, T.; Koubaa, Y.; Toumi, A. Application of feedforward neural network for induction machine rotor faults diagnostics using stator current. J. Electr. Syst. 2007, 3, 213-226.

33. Thomson, W.; Fenger, M. Current signature analysis to detect induction motor faults. IEEE Ind. Appl. Mag. 2001, 7, 26-34, doi: 10.1109/2943.930988. 
34. Nandi, S.; Toliyat, H.; Li, X. Condition monitoring and fault diagnosis of electrical motors-A review. IEEE Trans. Energy Convers. 2005, 20, 719-729, doi:10.1109/TEC.2005.847955.

35. Peña, H.; Ramirez, C.; Manecha, E. Fallas en los motores eléctricos de inducción. Causas, diagnósticos y medidas preventivas. Energía y Computación 1998, 3, 71-72.

36. Drozdowski, P.; Duda, A. Influence of magnetic saturation effects on the fault detection of induction motors. Arch. Electr. Eng. 2014, 63, 489-506, doi:10.2478/aee-2014-0035.

37. Narwade, S.; Kulkarni, P.; Partil, C. Fault detection of induction motor using current and vibration monitoring. Int. J. Adv. Comput. Res. 2013, 3, 272.

38. Kia, S.; Henao, H.; Capolino, G. A high-resolution frequency estimation method for three-phase induction machine fault detection. IEEE Trans. Ind. Electron. 2007, 54, 2305-2314, doi:10.1109/TIE.2007.899826.

39. Alarcón, C. Aportación al Mantenimiento Predictivo de Motores de Inducción Mediante Modernas Técnicas de Análisis de la Señal. Ph.D. Thesis, Institute of Energy Engineering, Universitat Politècnica de València, Valencia, Spain, 2012.

40. Henao, H.; Capolino, G.; Fernandez-Cabanas, M.; Filippetti, F.; Bruzzese, C.; Strangas, E.; Pusca, R.; Estima, J.; Riera-Guasp, M.; Hedayati-Kia, S. Trends in fault diagnosis for electrical machines: A review of diagnostic techniques. IEEE Ind. Electron. Mag. 2014, 8, 31-42, doi:10.1109/MIE.2013.2287651.

41. Duque-Perez, O.; Garcia-Escudero, L.A.; Morinigo-Sotelo, O.; Gardel, P.; Perez-Alonso, M. Analysis of fault signatures for the diagnosis of induction motors fed by voltage source inverters using ANOVA and additive models. Electr. Power Syst. Res. 2015, 121, 1-13.

42. Garcia-Escudero, L.; Duque-Perez, O.; Fernandez-Temprano, M.; Morinigo-Sotelo, D. Robust detection of incipient faults in VSI-fed induction motors using quality control charts. IEEE Trans. Ind. Appl. 2016, 53, 3076-3085, doi:10.1109/TIA.2016.2617300.

43. Hernandez, L.; Baladron, C.; Aguiar, J.; Carro, B.; Sanchez-Esguevillas, A.; Lloret, J.; Massana, J. A survey on electric power demand forecasting: Future trends in smart grids, microgrids and smart buildings. IEEE Commun. Surv. Tutor. 2014, 16, 1460-1495, doi:10.1109/SURV.2014.032014.00094.

44. Szabó, L.; Tóth, F.; Kovács, E.; Fekete, G. An overview on induction machine's diagnosis methods. J. Comput. Sci. Control Syst. 2008, 1, 229-234.

45. Soto, N.; De la Torre, F.; Diagnóstico de problemas de asimetrías rotóricas en un motor de inducción de gran potencia. Ingeniería Mecánica 2007, 10, 47-50.

46. Benbouzid, M.; Vieira, M.; Theys, C. Induction motors' faults detection and localization using stator current advanced signal processing techniques. IEEE Trans. Power Electron. 1999, 14, 14-22.

47. Baranski, M.; Decner, A.; Polak, A. Selected diagnostic methods of electrical machines operating in industrial conditions. IEEE Trans. Dielectr. Electr. Insul. 2014, 21, 2047-2054, doi:10.1109/TDEI.2014.004602.

48. Shnibha, R.; Albarbar, A.; Abouhnik, A.; Ibrahim, G. A more reliable method for monitoring the condition of three-phase induction motors based on their vibrations. ISRN Mech. Eng. 2012, 2012, 230-314, doi:10.5402/2012/230314.

49. Benbouzid, M.; Kliman, G. What stator current processing-based technique to use for induction motor rotor faults diagnosis? IEEE Trans. Energy Convers. 2003, 18, 238-244, doi:10.1109/TEC.2003.811741.

50. Filho, P.; Batista, F.; Pederiva, R.; Silva, V. Electrical fault diagnosis in induction motors using local extremes analysis. J. Q. Maint. Eng. 2016, 22, 321-332, doi:10.1108/JQME-07-2015-0026.

51. Villada, F.; Cadavid, D. Diagnostico de fallas en motores de inducción mediante la aplicación de redes neuronales artificiales. Inf. Tecnol. 2007, 18, 105-112.

52. Cusido, J.; Romeral, L.; Ortega, J.; Rosero, J.; Espinosa, A. Fault detection in induction machines using power spectral density in wavelet decomposition. IEEE Trans. Ind. Electron. 2008, 55, 633-643, doi:10.1109/TIE.2007.911960.

53. Allal, A.; Chetate, B. A new and best approach for early detection of rotor and stator faults in induction motors coupled to variable loads. Front. Energy 2016, 10, 176-191, doi:10.1007/s11708-015-0386-2.

54. Kohler, J.; Sottile, J.; Trutt, F. Alternatives for assessing the electrical integrity of induction motors. IEEE Trans. Ind. Appl. 1992, 28, 1109-1117, doi:10.1109/28.158836.

55. Filippetti, F.; Franceschini, G.; Tassoni. C.; Vas, P. AI techniques in induction machines diagnosis including the speed ripple effect. IEEE Trans. Ind. Appl. 1998, 34, 98-108, doi:10.1109/28.658729.

56. Chow, T.; Shi, H. Induction machine fault diagnostic analysis with wavelet technique. IEEE Trans. Ind. Electron. 2004, 51, 558-565, doi:10.1109/TIE.2004.825325. 
57. Aydın, I.; Karaköse, M.; Akın, E. Combined intelligent methods based on wireless sensor networks for condition monitoring and fault diagnosis. J. Intell. Manuf. 2005, 26, 717-729, doi:10.1007/s10845-013-0829-8.

58. Ding, L. A New Paradigm of Knowledge Engineering by Soft Computing, 1st ed.; World Scientific Publishing: London, UK, 2001; pp. 1-5; ISBN 109810245173.

59. Mosallam, A.; Medjaher, K.; Zerhouni, N. Time series trending for condition assessment and prognostics. J. Manuf. Technol. Manag. 2014, 25, 550-567, doi:10.1108/JMTM-04-2013-0037.

60. Zhao, M.; Lin, J.; Xu, X.; Lei, Y. Tacholess envelope order analysis and its application to fault detection of rolling element bearings with varying speeds. Sensors 2013, 13, 10856-10875, doi:10.3390/s130810856.

61. Arthur, N.; Penman, J. Induction machine condition monitoring with higher order spectra. IEEE Trans. Ind. Electron. 2000, 47, 1031-1041, doi:10.1109/IECON.1998.723031.

62. Eren, L.; Devaney, M. Bearing damage detection via wavelet packet decomposition of the stator current. IEEE Trans. Instrum. Meas. 2004, 53, 431-436, doi:10.1109/TIM.2004.823323.

63. Barbour, A.; Thomson, W. Finite element study of rotor slot designs with respect to current monitoring for detecting static airgap eccentricity in squirrel-cage induction motors. In Proceedings of the Conference Record of the 1997 IEEE Industry Application Conference, New Orleans, LA, USA, 5-9 October 1997; pp. 112-119.

64. Zhang, Z.; Wang, Y.; Wang, K. Fault diagnosis and prognosis using wavelet packet decomposition, Fourier transform and artificial neural network. J. Intell. Manuf. 2013, 24, 1213-1227, doi:10.1007/s10845-012-0657-2.

65. Ren, L.; Lv, W.; Jiang, S.; Xiao, Y. Fault diagnosis using a joint model based on sparse representation and SVM. IEEE Trans. Instrum. Meas. 2016, 65, 2313-2320, doi:10.1109/TIM.2016.2575318.

66. Son, J.; Ahn, B.; Ha, J.; Choi, B. An availability of MEMS-based accelerometers nd current sensors in machinery fault diagnosis. Measurement 2016, 94, 680-691, doi:10.1016/j.measurement.2016.08.035.

67. Camarena-Martinez, D.; Valtierra-Rodriguez, M.; Garcia-Perez, A.; Osornio-Rios, R.; Romero-Troncoso, R. Empirical mode decomposition and neural networks on FPGA for fault diagnosis in induction motors. Sci. World J. 2014, 2014, 908140.

68. Glowacz, A. Diagnostics of DC and Induction Motors Based on the Analysis of Acoustic Signals. Meas. Sci. Rev. 2014, 14, 257-262.

69. Li, B.; Chow, M.; Tipsuwan, Y.; Hung, J. Neural-network-based motor rolling bearing fault diagnosis. IEEE Trans. Ind. Electron. 2000, 47, 1060-1069, doi:10.1109/41.873214.

70. Ruiz-Gonzalez, R.; Gomez-Gil, J.; Martínez-Martínez, V. An SVM-Based classifier for estimating the state of various rotating components in agro-industrial machinery with a vibration signal acquired from a single point on the machine chassis. Sensors 2014, 14, 20713-20735, doi:10.3390/s141120713.

71. Su, H.; Chong, K. Induction machine condition monitoring using neural network modeling. IEEE Trans. Ind. Electron. 2007, 54, 241-249, doi: 10.1109/TIE.2006.888786.

72. Chudasama, K.; Shah, S. Induction motor relaying scheme for external faults detection and classification using subtractive clustering based sugeno fuzzy inference system. Electr. Power Compon. Syst. 2016, 44, 1149-1162, doi:10.1080/15325008.2016.1149255.

73. Dash, R.; Subudhi, B. Stator inter-turn fault detection of an induction motor using neuro-fuzzy techniques. Arch. Control Sci. 2010, 20, 363-376, doi:10.1080/15325008.2016.1149255.

74. Mortada, M.; Yacout, S.; Lakis, A. Diagnosis of rotor bearings using logical analysis of data. J. Q. Maint. Eng. 2011, 17, 371-397, doi:10.1108/13552511111180186.

75. Ranga, C.; Chandel, A. Advanced tool based condition monitoring of induction machines by using labVIEW-A review. In Proceedings of the IEEE UP Section Conference of Electical Computer and. Electronics (UPCON), Allahabad, India, 4-6 December 2015; pp. 1-6.

76. Zilouchian, A.; Jamshidi, M. Intelleging Control Systems Using Soft Computing Methodologies, 1st ed.; CRC Press: Boca Raton, FL, USA, 2000; ISBN 0-8493-1875-0.

77. Kobbacy, K.; Vadera, S.; A survey of AI in operations management from 2005 to 2009. J. Manuf. Technol. Manag. 2011, 22, 706-733, doi:10.1108/17410381111149602.

78. Pracash, A. Perfomance Monitoring of Wind Turbines-A data Mining Approach. Ph.D. Thesis, Graduate College, Iowa University, Iowa, IA, USA, 2012.

79. Cardoso, A.; Saraiva, E. Computer-aided detection of airgap eccentricity in operating three-phase induction motors by Park's vector approach. IEEE Trans. Ind. Appl. 1993, 29, 897-901, doi:10.1109/28.245712. 
80. Kyusung, K.; Parlos, A. Induction motor fault diagnosis based on neuropredictors and wavelet signal processing. IEEE/ASME Trans. Mech. 2002, 7, 201-219, doi:10.1109/TMECH.2002.1011258.

81. Khireddine, M.; Slimane, N.; Abdessemed, Y.; Makhloufi, M. Fault Detection and Diagnosis in Induction Motor Using Artificial Intelligence Technique. MATEC Web of Conferences. 2014. Volume 16. Available online: https://www.matec-conferences.org/articles/matecconf/pdf/2014/07/matecconf_csndd2014_10004.pdf (accessed on 16 February 2017).

82. Kumar, E.; Chaturvedi, S.; Deshpande, A. Maintenance of industrial equipment. Int. J. Q. Reliab. Manag. 2009, 26, 196-211, doi:10.1109/UPCON.2015.7456693.

83. Moosavian, M.; Ahmadi, H.; Sakhaei, B.; Labbafi, R. Support vector machine and K-nearest neighbour for unbalanced fault detection. J. Q. Maint. Eng. 2014, 20, 65-75, doi:10.1108/JQME-04-2012-0016.

84. Jayaswal, P.; Verma, S.; Wadhwani, A. Application of ANN, fuzzy logic and wavelet transform in machine fault diagnosis using vibration signal analysis. J. Q. Maint. Eng. 2010, 16, 190-213, doi:10.1108/13552511011048922.

85. Jalali, M.; Farokhzad, S.; Abad, A. Vibration based fault detection of alternator by fast fourier transform and adaptive neuro fuzzy inference system. J. Curr. Res. Sci. 2013, 1, 221-226.

(C) 2017 by the authors. Licensee MDPI, Basel, Switzerland. This article is an open access article distributed under the terms and conditions of the Creative Commons Attribution (CC BY) license (http://creativecommons.org/licenses/by/4.0/). 